\title{
Protection against ischemia/reperfusion: role of the farnesol and red palm oil
}

\author{
$\mathrm{PhD}$ Thesis
}

\section{Gergő Szücs MD}

Cardiovascular Research Group

Department of Biochemistry

University of Szeged

$$
\text { Szeged, } 2013
$$

Supervisor:

Csaba Csonka MD PhD

Cardiovascular Research Group, Department of Biochemistry, University of Szeged 


\section{TABLE OF CONTENTS}

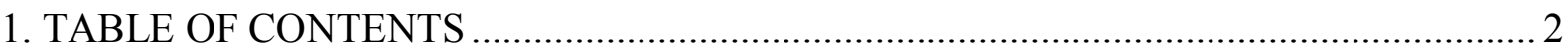

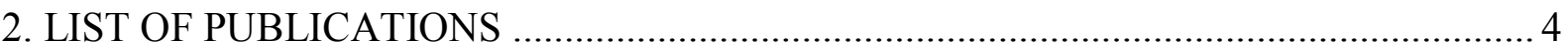

2.1 List of full papers directly related to the subject of thesis ......................................... 4

2.2 List of full papers indirectly related to the subject of thesis.......................................... 4

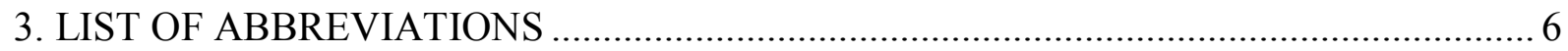

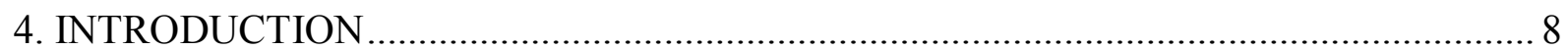

4.1 Acute myocardial infarction and ischemia/reperfusion injury ................................... 8

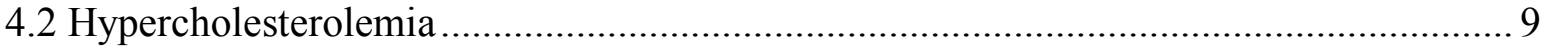

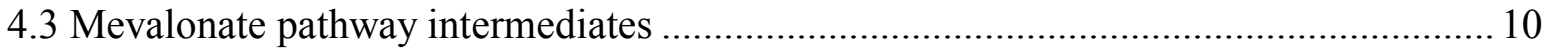

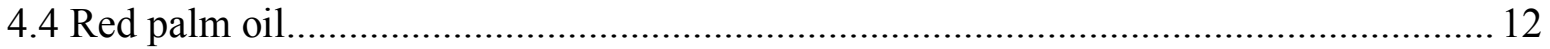

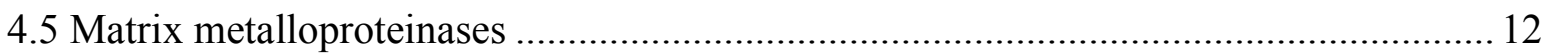

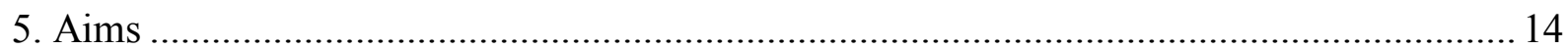

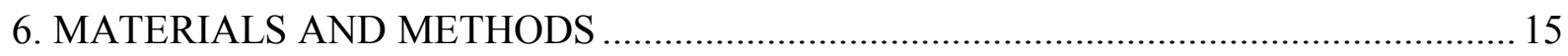

6.1. Experimental design and isolated heart perfusion protocol of study 1 ........................ 15

6.2. Experimental design and isolated heart perfusion protocol of study $2 \ldots \ldots \ldots \ldots \ldots \ldots \ldots \ldots . . . . . . .16$

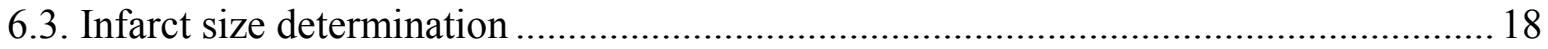

6.4. Measurement of myocardial protein geranylgeranylation and farnesylation ................ 18

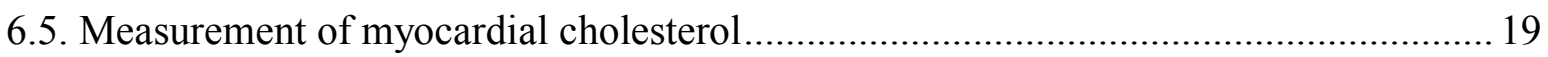

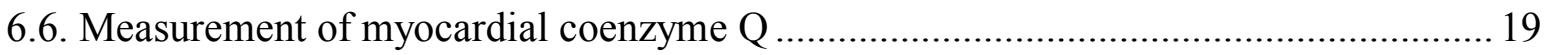

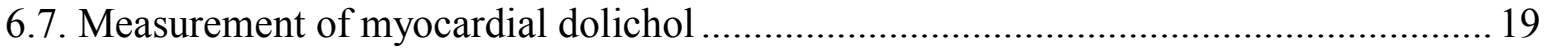

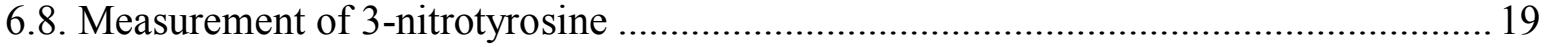

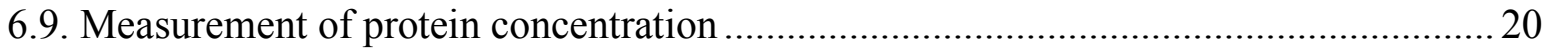

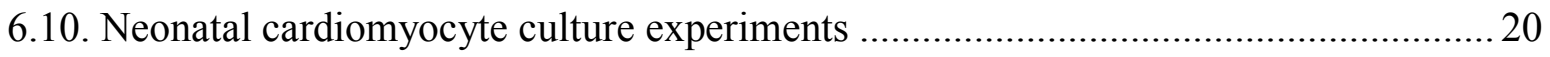

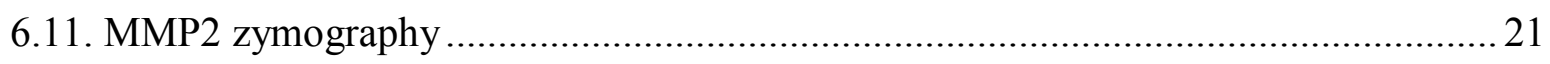

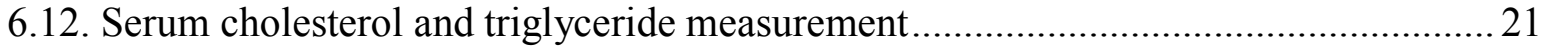

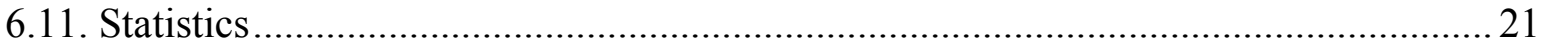

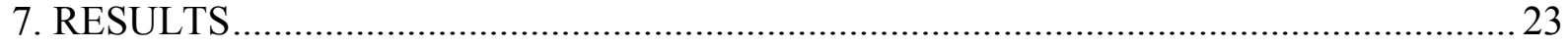

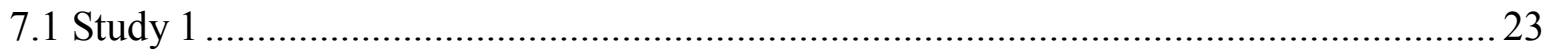

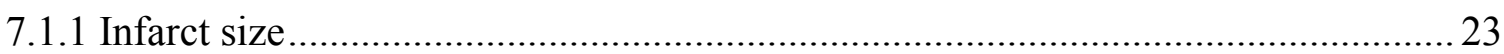

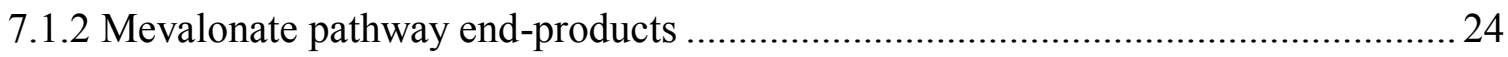




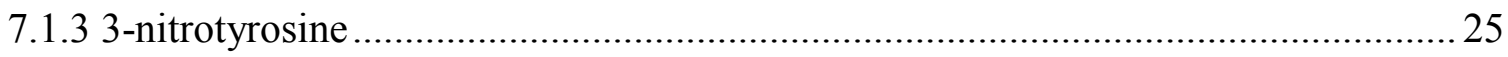

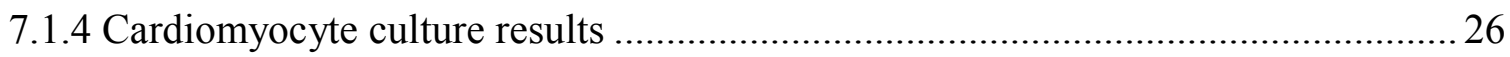

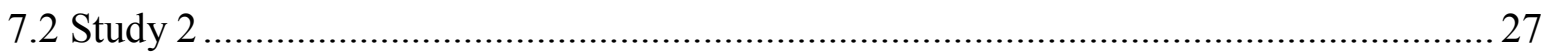

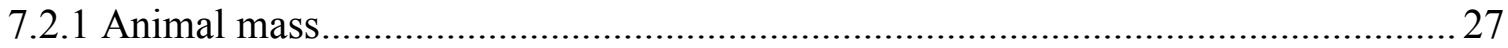

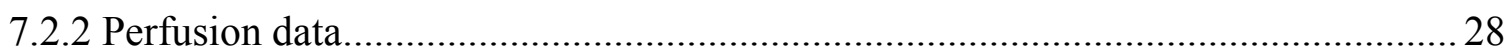

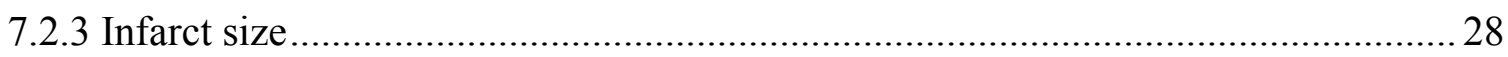

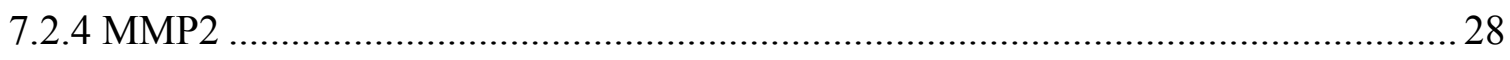

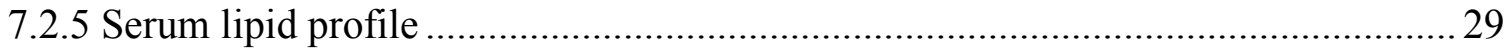

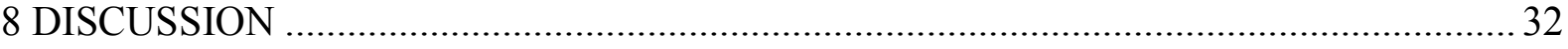

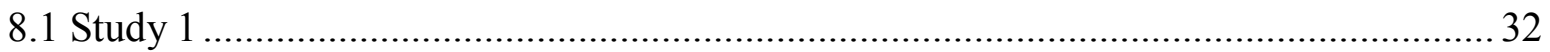

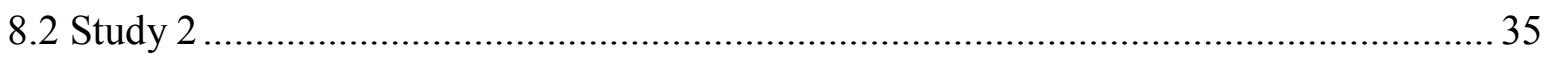

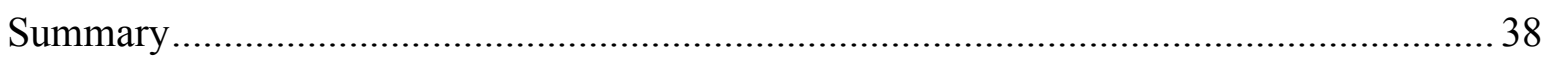

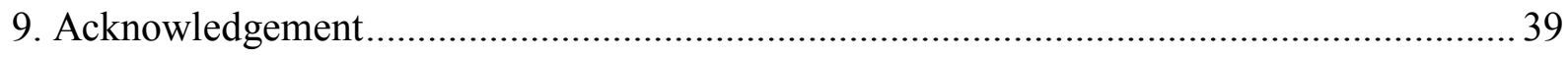

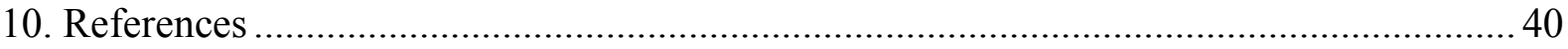




\section{LIST OF PUBLICATIONS}

\subsection{List of full papers directly related to the subject of thesis}

I. Cardioprotection by Farnesol: Role of the Mevalonate Pathway. Szúcs G, Murlasits Z, Török S, Kocsis GF, Pálóczi J, Görbe A, Csont T, Csonka C, Ferdinandy P. Cardiovasc Drugs Ther. 2013 Aug;27(4):269-77.

IF.: 2.673

II. Dietary red palm oil supplementation decreases infarct size in cholesterol fed rats. Szucs G, Bester DJ, Kupai K, Csont T, Csonka C, Esterhuyse AJ, Ferdinandy P, Van Rooyen J. Lipids Health Dis. 2011 Jun 20;10:103.

IF.: 2.170

Cumulative impact factor of papers directly related to the thesis: 4.843

\subsection{List of full papers indirectly related to the subject of thesis}

I. MicroRNA-25-dependent up-regulation of NADPH oxidase 4 (NOX4) mediates hypercholesterolemia-induced oxidative/nitrative stress and subsequent dysfunction in the heart. Varga ZV, Kupai K, Szúcs G, Gáspár R, Pálóczi J, Faragó N, Zvara A, Puskás LG, Rázga Z, Tiszlavicz L, Bencsik P, Görbe A, Csonka C, Ferdinandy P, Csont T. J Mol Cell Cardiol. 2013 Sep;62:111-21.

\section{IF.: 5.148}

II. Metabolic syndrome influences cardiac gene expression pattern at the transcript level in male ZDF rats. Sárközy M, Zvara A, Gyémánt N, Fekete V, Kocsis GF, Pipis J, Szücs G, Csonka C, Puskás LG, Ferdinandy P, Csont T. Cardiovasc Diabetol. 2013 Jan $15 ; 12(1): 16$.

\section{IF.: 4.209}

III. Dietary red palm oil supplementation reduces myocardial infarct size in an isolated perfused rat heart model. Bester DJ, Kupai K, Csont T, Szucs G, Csonka C, Esterhuyse AJ, Ferdinandy P, Van Rooyen J. Lipids Health Dis. 2010 Jun 18;9:64.

IF.: 2.239

IV. Matrix metalloproteinase activity assays: Importance of zymography. Kupai K, Szucs G, Cseh S, Hajdu I, Csonka C, Csont T, Ferdinandy P. J Pharmacol Toxicol Methods. 2010 Mar-Apr;61(2):205-9. 
IF.: 2.22 (Scopus)

Cumulative impact factor of papers indirectly related to the thesis: $\mathbf{1 1 . 5 9 6}$ 


\section{LIST OF ABBREVIATIONS}

ATP

$\mathrm{Na}^{+}-\mathrm{K}^{+}$-ATPase

SERCA

$\mathrm{Na}^{+}$

$\mathrm{H}^{+}$

$\mathrm{HCO}^{-}$

$\mathrm{Ca}^{2+}$

ROS

DNA

MMP

HMG-CoA reductase enzyme

GTPase

NO

RPO

SRC

iv

HPLC

$\mathrm{KOH}$

ELISA

$\mathrm{Ig}$

BCA

DMEM

FBS

$\mathrm{N}_{2}$

$\mathrm{CO}_{2}$

DMSO

SEM

ANOVA

AU adenosine triphosphate

Sodium-potassium adenosine triphosphatase

sarco/endoplasmic reticulum $\mathrm{Ca}^{2+}$-ATPase

sodium ion

proton

bicarbonate

calcium ion

reactive oxygen species

deoxyribonucleic acid

matrix metalloproteinase

3-hydroxy-3-methyl-glutaryl-Coenzyme A reductase enzyme

guanosine triphosphate phosphatase enzyme

nitrogen monoxide

red palm oil

standard rat chow

intravenous

high performance liquid chromatography

potassium hydroxide

enzyme-linked immunosorbent assay

immunoglobulin

bicinchoninic acid

Dulbecco's modified Eagle's medium

fetal bovine serum

nitrogen gas

carbon dioxide

dimethyl sulfoxide

standard error of the mean

analysis of variance

arbitrary unit 
CE

coronary effluent

HR

heart rate

BPM

beats per minute

JNK

c-Jun N-terminal kinase

ERK

extracellular-signal-regulated kinases 


\section{INTRODUCTION}

\subsection{Acute myocardial infarction and ischemia/reperfusion injury}

Ischemic heart diseases are currently the leading causes of morbidity and mortality in the world [1]. About $70 \%$ of the people with ischemic heart disease die due to an acute myocardial infarction [2]. From being an illness seen predominantly in developed countries including Hungary, myocardial infarction is now becoming increasingly more common in developing countries as well [3]. Myocardial infarction has several risk factors such as hyperlipidemia, atherosclerosis, obesity, diabetes mellitus, heart failure, high blood pressure, smoking as well as age and gender.

Myocardial ischemia can be described as an imbalance between oxygen and nutrient supply and demand of myocardial tissue. Specifically, myocardial hypertrophy and accelerated heart rhythm can enhance oxygen demand, while supply is hampered by partial or complete coronary artery occlusion. Coronary occlusion usually is a result of a thrombotic event such as rupture of a vulnerable atherosclerotic plaque, formation of a thrombus on the erosion of the lesion, or embolization. The definitive therapy for myocardial infarction is still the rapid reclamation of blood flow to the ischemic zone of myocardium, as percutaneous coronary intervention or if it is not available, thrombolytic therapy. Early reperfusion at least partly saves ischemic myocardium; however, reperfusion exacerbates further complications such as diminished cardiac contractile function (stunning) and arrhythmias. Therefore the prevention of ischemic heart disease is very important to avoid the enormous clinical, economic, and social costs of cardiovascular disease. The mechanism, how ischemia damage myocardial tissue, is very complex and not exactly known in details. Decreased oxygen and nutrient supply cause energy depletion via decreasing the ATP production of the myocardium and thus impair transport function (e.g. ouabain-sensitive $\mathrm{Na}^{+}, \mathrm{K}^{+}$-ATPase, SERCA), function of protein kinase enzymes, protein synthesis, etc. Under ischemic conditions the decrease in pH stimulates $\mathrm{Na}^{+}-\mathrm{H}^{+}$exchange and $\mathrm{Na}^{+}-\mathrm{HCO}_{3}{ }^{-}$transporter, which leads to intracellular sodium accumulation and development of intracellular $\mathrm{Ca}^{2+}$ overload [4] which activates proapoptotic signaling [5]. Energy depletion results opening of the mitochondrial permeability transition pore, mitochondrial swelling and apoptosis. Derangement of the mitochondrial electron transport system promotes the generation of reactive oxygen species (ROS) and 
development of oxidative stress in the ischemic heart. ROS react directly with cellular lipids, proteins and DNA leading to cell injury/death [6]. ROS are able to influence extracellular matrix remodeling through the activation of matrix metalloproteinases (MMPs) [7]. Reestablishment of adequate oxygen and nutrients can limit the size of the ultimate area of infarction. Paradoxically, restoration of normal blood flow to an area of ischemia results in a complex cascade of inflammation and further oxidative stress. Ischemia/reperfusion results in the loss of contractile function and produces myocardial damage as a consequence of cell death from both necrosis and apoptosis [8]. The process involves damage caused by ischemia and reperfusion is called ischemia/reperfusion injury. The development of effective cardioprotective agents and pretreatments against ischemia/reperfusion injury is of great importance and remains a foremost experimental goal of heart research [9].

\subsection{Hypercholesterolemia}

Incidence of metabolic syndrome including obesity, diabetes mellitus, high blood pressure, and dyslipidemia is constantly growing worldwide. These diseases especially hypercholesterolemia are a well-known risk factor for atherosclerosis and, therefore, coronary heart diseases, including myocardial infarction. Hypercholesterolemia usually results from nutritional factors such as a diet high in saturated fats, sucrose, and fructose combined with decreased physical activity, obesity, and underlying polygenic predispositions [10]. It is well known, that hypercholesterolemia increases the incidence of cardiovascular diseases through atherosclerosis; however, several studies have shown that hypercholesterolemia exerts direct myocardial effects independent of the development of atherosclerosis both in humans [11-13] and animal models [14-21]. Different animal models are used to study hypercholesterolemia. The human lipid profile and lipid profile of animal models are different and these differences allow studying different aspects of hypercholesterolemia. We used the hearts of male Wistar rats to study the direct cardiac effects of dietary cholesterol as rats show moderate increase in serum cholesterol level due to a high-cholesterol diet without substantial development of atherosclerosis [16,22,23]. Hypercholesterolemia independently from the vascular effects negatively influences myocardial performance: impairs systolic as well as diastolic contractile function [14-16], aggravates the deleterious effects of ischemia/reperfusion injury [17], and interferes with the anti-ischemic effect of ischemic pre- $[16,18,24]$ and postconditioning [25] (endogenous cardioprotective mechanisms). Furthermore, it has been shown that myocardial 
function impaired in cholesterol fed rats and this impaired function is in connection with increased peroxynitrite level caused by cholesterol [14,20,21]. Cholesterol is the bulk endproduct of the mevalonate pathway [26]. HMG-CoA reductase enzyme is the rate limiting step of mevalonate pathway (Figure 1) and therefore, it is highly regulated. The end product cholesterol represses the transcription of the HMG-CoA reductase gene [27]. The most commonly used cholesterol lowering drugs, statins, are competitive inhibitors of HMG-CoA reductase enzyme [28]. In humans a number of large clinical trials have shown that chronic administration of statins have potent cholesterol-lowering effects and reduce cardiovascular morbidity and mortality $[29,30]$. On the other hand, it is well known that chronic treatment with statins may exhibit a number of extrahepatic adverse effects, such as myopathy and rhabdomyolysis [31]. Therefore, it is reasonable to develop new, safer therapeutic tool to influence mevalonate pathway.

\subsection{Mevalonate pathway intermediates}

Farnesol (3,7,11-trimethyl-2,6,10-dodecatriene-1-ol), a 15-carbon sesquiterpenoid molecule, increases the degradation of HMG-CoA reductase enzyme [32]. Bentinger et al. (1998) has shown in rats that farnesol could be phosphorylated in vivo to form farnesylpyrophosphate [33] which is a key branching point in the mevalonate pathway [26] (Figure 1) and, therefore, farnesol is able to modulate the mevalonate pathway [34]. We have previously shown that administration of farnesol restored the protective effect of preconditioning in cholesterol fed rats [9,35]; however, it is not known if farnesol itself is able to protect the heart against ischemia/reperfusion injury. Farnesol is naturally occurring mainly in aromatic fruits [36] and is known as a powerful antioxidant [36-38]. Farnesyl-pyrophosphate can be further metabolized to the mevalonate pathway end-products i.e. cholesterol, coenzyme Q, and dolichol [26]. Moreover, farnesyl-pyrophosphate is a precursor for the prenylation (farnesylation and/or geranylgeranylation) of several intracellular proteins. Protein prenylation is a common post-translational modification of several intracellular proteins [26,39] (Figure 1) and prerequisite for their physiological function. Examples of prenylated proteins include the $\gamma$ subunit of heterotrimeric G-proteins, nuclear lamins, and some members of the Ras superfamily of small GTPases e.g.: Ras, Rho, Rac, Rab subfamily [4042]. Although several G-proteins are involved in the signal-transduction of 
ischemia/reperfusion injury and cardioprotection, the role of their prenylation has not been investigated in ischemia/reperfusion injury.

Farnesyl pyrophosphate is also a precursor for the synthesis of different forms of coenzyme Q such as coenzyme Q10 that is most common coenzyme Q in humans and coenzyme Q9 that is most common in rats [43] (Figure 1). Coenzyme Q plays a major role in the mitochondrial electron-transport chain and serves as an endogenous antioxidant [43]. Coenzyme $\mathrm{Q}$ is protective against myocardial ischemia/reperfusion-injury in animal studies $[44,45]$ and it is a registered drug for adjuvant therapy of heart failure worldwide.

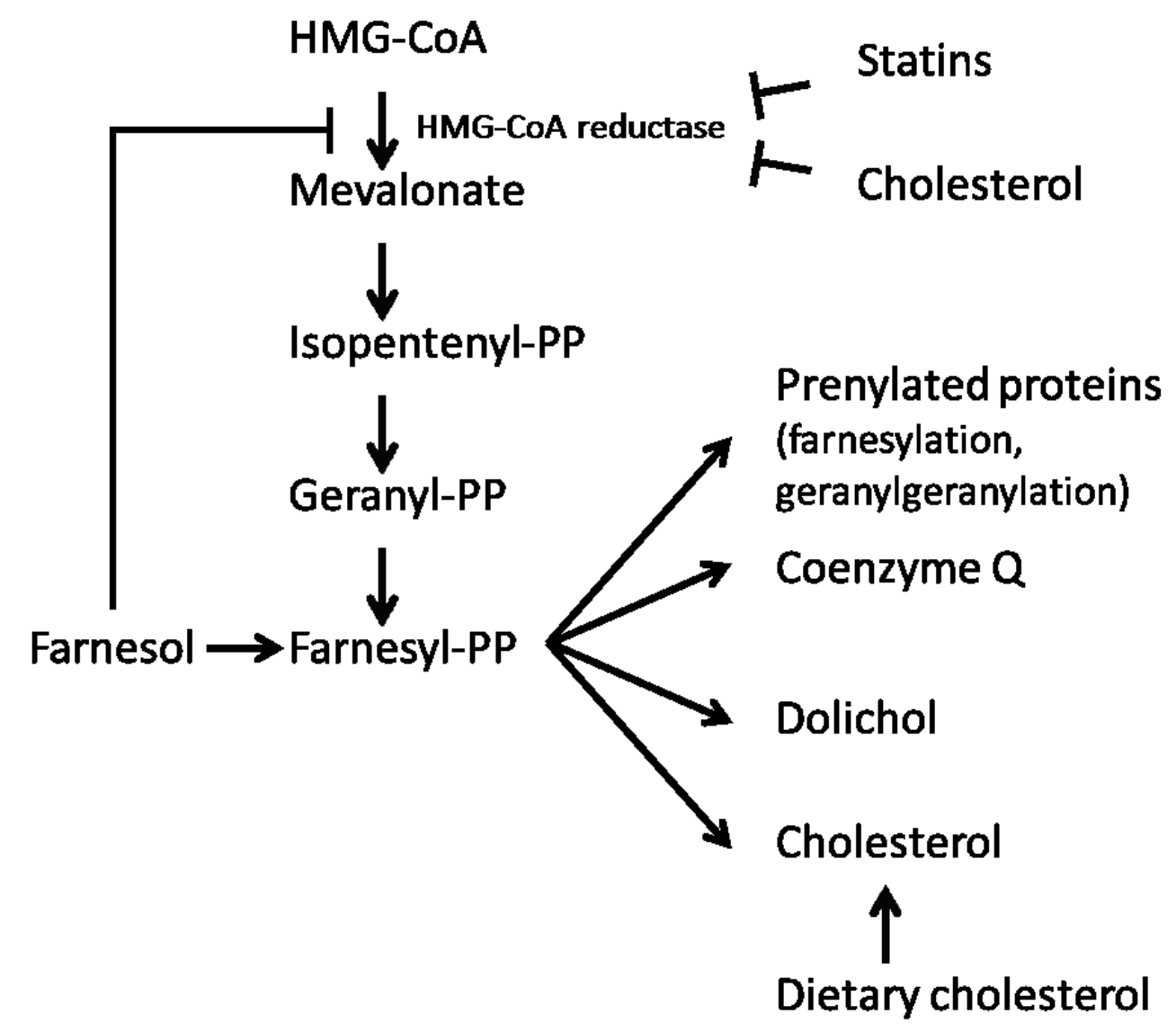

Figure 1. The mevalonate pathway.

Dolichol, another derivative of farnesyl pyrophosphate (Figure 1), is the most prevalent polyisoprenyl glycosyl carrier in eukaryotes involved in C- [46] and Omannosylaton of proteins, the formation of glycosylphosphatidylinositol anchors [47] and the $\mathrm{N}$-glycosylation of proteins [48]. The role of dolichol in ischemia/reperfusion is not known. 
Farnesol has been shown to exert an antioxidant effect in-vivo [36-38] and to restore reduced glutathione, glutathione reductase and glutathione peroxidase levels [36-38]. The above findings may support the potential cardioprotective effect of farnesol, since reactive oxygen and nitrogen species e.g. peroxynitrite formed nonenzymatically from NO and superoxide, play a pivotal role in ischemia/reperfusion injury $[49,50]$.

\subsection{Red palm oil}

Red palm oil (RPO) is a natural oil obtained from oil palm fruit (Elaeis guineensis). $\mathrm{RPO}$ is an antioxidant rich oil which contains approximately $50 \%$ saturated and $50 \%$ unsaturated fatty acids $[51,52]$. Carotenoids and vitamin E (75\% of which is tocotrienol) are the most abundant antioxidants in this oil. Both of these antioxidants are contained at a level of at least $500 \mathrm{ppm}$ in RPO [51,52]. The cocktail of antioxidants within RPO is believed to have synergistic effects [53,54]. The oil offers cardioprotection, by activation of several different protective pathways which work synergistically together [55]. Dietary RPO supplementation has previously been shown to offer protection against ischemia/reperfusion injury in the isolated perfused heart [56-58]. Esterhuyse and co-workers (2005) [56] showed that dietary RPO supplementation could improve post ischemic functional recovery in rats fed a standard rat chow diet (SRC), and rats fed a SRC plus 2\% cholesterol for six weeks [56]. They suggested that RPO mediated protection against ischemia/reperfusion injury may be induced through different pathways in hearts of SRC fed and cholesterol fed rats.

\subsection{Matrix metalloproteinases}

Matrix metalloproteinases (MMPs) are a large family of zinc dependent endopeptidases that recognized for their ability to remodel the extracellular matrix [59]. MMPs involved in remodeling the extracellular matrix during various physiological functions such as embryonic development, angiogenesis, morphogenesis, wound healing, tissue repair and play a role in several pathological conditions such as cancer, cardiovascular disease, arthritis, inflammation, diabetes, etc. $[19,60]$. There are evidences that in pathological condition MMPs are able to proteolytically cleave intracellular proteins [61]. MMPs are synthesized in a latent form (zymogen or pro-MMP), and are activated by proteolytic cleavage of an amino terminal domain or by conformational changes induced by denaturing agents or oxidative stress molecules such as peroxynitrite. Normally MMPs are activated by 
removal of the autoinhibitory propeptide domain by proteases resulting in an active truncated MMP. Recently it was found that MMP2 plays a role in ischemia/reperfusion damage in the heart [62] as ischemia induced activation and release of MMP-2 is a major effector of acute mechanical dysfunction after ischemia/reperfusion in rat hearts [62-64]. Increased MMP2 activity has also been associated with hypercholesterolemic diets [9]. This may be due to the increased peroxynitrite production within the myocardium [14]. ROS and peroxynitrite have been shown to activate MMP2 through redox modification of the regulatory site of this enzyme [19,65-68]. This redox modification leads to activity being displayed in the 75 and 72 $\mathrm{kDa}$ isoforms of the enzyme, while only the $64 \mathrm{kDa}$ isoform is active if MMP2 is activated in the classical manner $[19,66]$. Activated MMP2 damages cardiomyocytes during reperfusion. This is achieved by cleaving the contractile protein regulatory element, troponin I and possibly other structural and cytoskeletal proteins [61,69-73]. Activation of MMP2 during an ischemic insult is therefore, normally associated with decreased functional recovery and larger infarct size of the heart [62,74-77]. This has been confirmed through inhibition of MMP2 by antibodies or chemical agents [78-82]. The RPO has antioxidant properties and therefore, may inhibit the peroxynitrite induced activation of MMP2.

In a recent study [83] it was shown that red palm oil reduced infarct size in a model of ischemia/reperfusion injury. However, this model investigated only hearts of healthy animals. The intention of the current study was therefore, to use a high cholesterol feeding model to ensure that the model is more clinically relevant and to establish confirmation that red palm oil protection are indeed applicable in unhealthy diets, as was previously argued. In all red palm oil fed studies up to date [55-58], results have indicated post-ischemic involvement of certain cellular biochemical pathways. However, none of these studies provided any evidence of pre-ischemic protection by red palm oil. Mechanism of RPO induced protection is not known; however, we hypothesized that RPO may attenuate peroxynitrite induced MMP activation. 


\section{Aims}

The aims of this study were: 1) to investigate the cardioprotective effect of farnesol and 2) to determine whether the antioxidant effect of farnesol or the increased coenzyme Q, protein prenylation and dolichol formation may protect myocardium against ischemia/reperfusion injury. Furthermore, our aims were 3) to investigate the effects of dietary RPO supplementation on myocardial infarct size in the hearts of rats on a cholesterol enriched diet and 4) to determine whether MMP2 activity was altered by RPO supplementation, both pre- and postischemically. 


\section{MATERIALS AND METHODS}

This investigation conformed to the National Institutes of Health Guide for the Care and Use of Laboratory Animals (NIH Pub. No. 85-23, Revised 1996) and was approved by the local ethics committee at the University of Szeged.

\subsection{Experimental design and isolated heart perfusion protocol of study 1}

Here we assessed the effect of subchronic farnesol treatment on ischemic tolerance and biochemical changes of the heart.

Male Wistar rats (300-400 g, $\mathrm{n}=108$ in the entire study 1) were kept under controlled temperature with 12/12h light/dark cycles. They received a standard rodent chow and tap water ad libitum. Rats were randomly assigned to the following groups: oral administration of vehicle $(2.5 \%$ methylcellulose) or $0.2,1,5$, and $50 \mathrm{mg} / \mathrm{kg} /$ day farnesol (SAFC Supply Solution, St Louis, MO), respectively for 12 days. The length of farnesol administration and doses were applied according to previous studies [36,84].

On day 13, the effect of farnesol on cardiac ischemic tolerance and biochemical changes was tested. Therefore, rats were anesthetized, heparin (500 U/kg iv) was administered, and hearts were isolated and perfused at $37^{\circ} \mathrm{C}$ in Langendorff mode with oxygenated Krebs-Henseleit buffer with constant pressure as previously described [35,84]. Hearts were subjected either to (i) $30 \mathrm{~min}$ coronary occlusion followed by $120 \mathrm{~min}$ reperfusion to measure infarct size in all groups ( $\mathrm{n}=12-14$ except for the $0.2 \mathrm{mg} / \mathrm{kg} / \mathrm{day}$ farnesol treated group where $\mathrm{n}=8$ ) or to (ii) $10 \mathrm{~min}$ of perfusion to wash out blood before tissue sampling for biochemical assays from selected groups as appropriate (see results). Cardiac levels of mevalonate pathway end-products (prenylated proteins, cholesterol, coenzyme Q9, Q10, and dolichol; $\mathrm{n}=13$ in the vehicle and the $1 \mathrm{mg} / \mathrm{kg} /$ day farnesol treated group), and 3-nitrotyrosine (marker of oxidative/nitrosative stress, $n=7$ in the vehicle and the 1 and $50 \mathrm{mg} / \mathrm{kg} /$ day farnesol treated group) were measured from the tissue samples in separate experiments, respectively (Figure 2). Background morphological and hemodynamical parameters such as body weight, heart weight, and coronary flow before ischemia were measured from all animals served for infarct size measurement and assessment of biochemical parameters (Table 1). 
Oral treatments in vivo

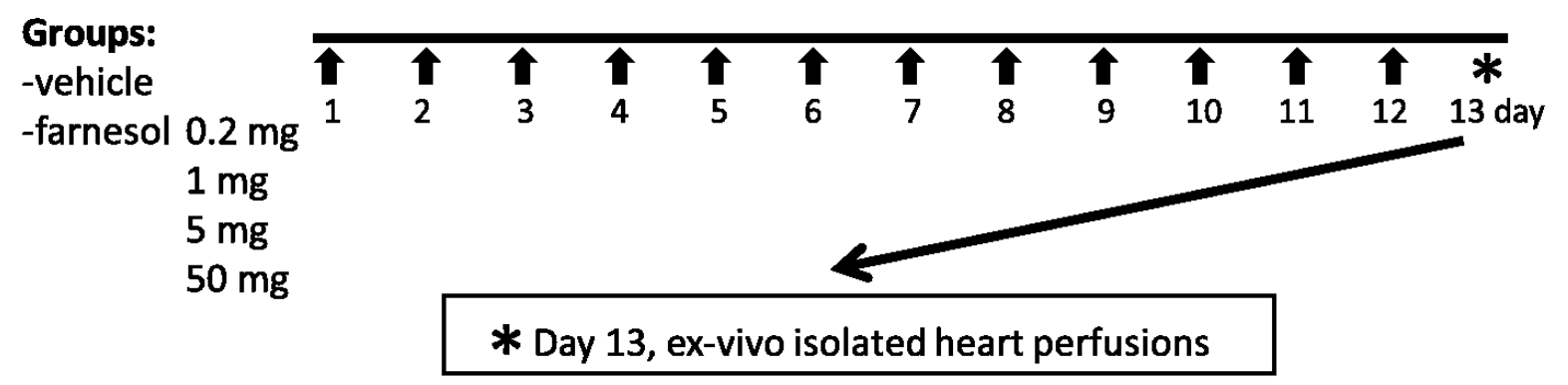

Perfusion protocol to test ischemic tolerance:

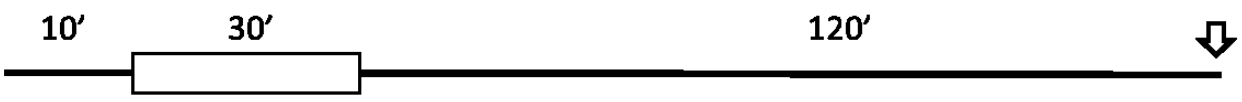

Perfusion protocol for biochemical assays:

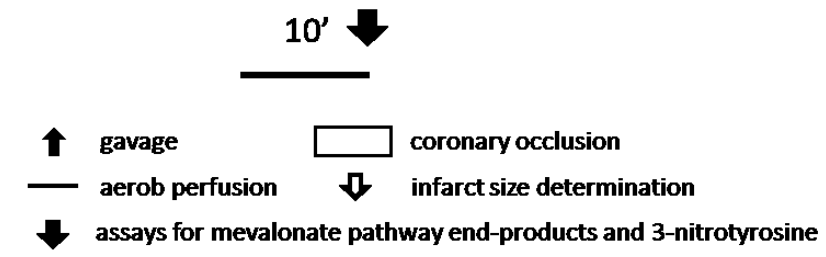

Figure 2. Experimental protocol of study 1. Male Wistar rats were treated with vehicle (2.5\% methylcellulose) or $0.2,1,5$, and $50 \mathrm{mg} / \mathrm{kg} /$ day farnesol, respectively for 12 days per os by gavage. On day 13 , hearts were isolated to test the effect of the different treatments on cardiac ischemic tolerance and biochemical changes. To test ischemic tolerance, hearts from all groups were subjected to 30 min coronary occlusion followed by 120 min reperfusion to measure infarct size. To measure changes in cardiac biochemical parameters from selected groups, hearts were subjected to $10 \mathrm{~min}$ of aerobic perfusion to wash out blood before tissue sampling.

\subsection{Experimental design and isolated heart perfusion protocol of study 2}

Male Wistar rats were divided into four groups. Rats in these groups were placed on the following diets, respectively:

Group 1: Standard rat chow diet for 9 weeks (Norm)

Group 2: 2\% cholesterol-enriched diet for 9 weeks (Chol)

Group 3: Standard rat chow supplemented with $200 \mu \mathrm{RPO}$ (Norm+RPO) per day for the last 5 weeks of the 9 week period 
Group 4: 2\% cholesterol-enriched diet for nine weeks supplemented with $200 \mu 1$ RPO per day for the last 5 weeks of the 9 week period (Chol+RPO)

Rats were individually housed to ensure that each animal received equal amounts of supplements. RPO and supplements were prepared on a daily basis in order to prevent spoiling. The red palm oil doses were applied according to previous studies [85]. Rats were allowed ad libitum access to food and water.

\section{Oral treatments in vivo}

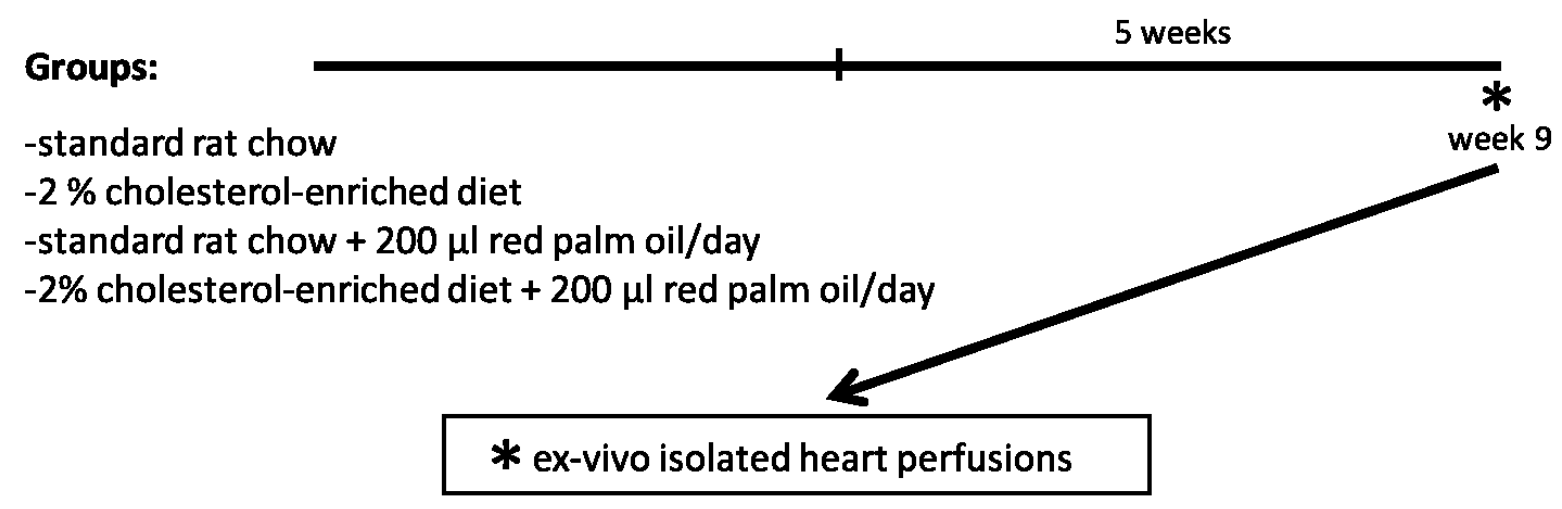

Perfusion protocol to test ischemic tolerance:

\begin{tabular}{llll}
$10^{\prime}$ & $10^{\prime}$ & $120^{\prime}$ & 7 \\
\hline & $10^{\prime}$ &
\end{tabular}

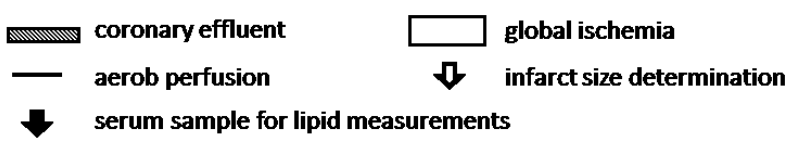

Figure 3. Experimental protocol of study 2. Male Wistar rats were fed with standard rat chow or $2 \%$ cholesterol supplemented rat chow for 9 weeks with or without red palm oil supplementation in the last 5 weeks. To assess ischemic tolerance hearts were subjected to 30 min global ischemia followed by 120 min reperfusion. Serum samples were taken from rats before perfusion protocol to assess serum cholesterol and serum triglyceride levels. Coronary effluents were collected before and after ischemia to assess cardiac MMP2 activity.

After the feeding period, rats were anaesthetized using diethyl ether. Hearts were isolated, mounted on a Langendorff perfusion apparatus, and were perfused at $37^{\circ} \mathrm{C}$ using a Krebs-Henseleit buffer solution which was constantly gassed with 5\% carbon dioxide, 95\% 
oxygen and a constant perfusion pressure of $100 \mathrm{cmH}_{2} 0$ was maintained. After mounting, hearts were subjected to 10 minutes of stabilization, followed by 30 minutes of normothermic global ischemia and 120 minutes of reperfusion. At the end of the perfusion protocol infarct size was measured.

\subsection{Infarct size determination}

To assess ischemic tolerance of the heart, infarct size was measured as follows. In case of coronary occlusion (study 1) at the end of the perfusion protocol, the coronary artery was reoccluded and $5 \mathrm{ml}$ of $0.1 \%$ Evans blue dye was injected into the aorta to delineate the area at risk zone and after that the hearts were frozen. In case of global ischemia (study 2) the hearts were frozen without Evans blue dying. Frozen hearts were then sliced, and incubated for $10 \mathrm{~min}$ at $37^{\circ} \mathrm{C}$ in $1 \%$ triphenyltetrazolium chloride to delineate infarcted tissue. Slices were then fixed in formalin solution $10 \mathrm{~min}$ at $37^{\circ} \mathrm{C}$ and then placed in phosphate buffer $(\mathrm{pH}$ 7.4) $[84,86]$. Heart slices were then placed between two sheets of glass and scanned into a computer and analyzed using infarct size planimetry software (Infarctsize ${ }^{\mathrm{TM}} 2.4$ Pharmahungary, Szeged, Hungary) in a blinded manner. Infarct size was expressed as a percentage of the area at risk. In case of coronary occlusion (study 1) the area at risk was calculated as a percentage of the total ventricular area $[84,86]$. In case of global ischemia (study 2) the area at risk was the total ventricular area $[84,86]$.

\subsection{Measurement of myocardial protein geranylgeranylation and farnesylation}

The nucleophilic cleavage of the allylic thiol bond by 2-naphthol provides for quantitative determination of the cysteine-bound prenyl groups of prenylated proteins. The level of cysteine-bound farnesyl and geranylgeranyl groups were measured by HPLC method as previously described [87]. Briefly, $200 \mathrm{mg}$ tissue samples were delipidated by extraction with ethanol followed by diethyl ether. Delipidated samples were mixed with $2.5 \mathrm{ml}$ reagent mixture $(20 \mathrm{mg} / \mathrm{mL}$ potassium naphthoxide dissolved in dioxane). Then dioxane was removed with a stream of nitrogen gas and $100 \mu$ dimethylformamide was added to the samples and were heated at $100^{\circ} \mathrm{C}$ for 8 hours. The reaction products were extracted with $400 \mu \mathrm{n}$-hexane and the upper phase was injected to YL9100 HPLC system on a YMC-Pack ODS-A 250 $\mathrm{mm} \times 4.6 \mathrm{~mm}$ ID $5 \mu \mathrm{m}$ using $95-100 \%$ acetonitrile as mobile phase. Calibration curves were made using $\mathrm{N}$-acetyl-S-farnesyl-L-cysteine and N-acetyl-S-geranylgeranyl-L-cysteine 
standards (Sigma, St. Louis, MO) underwent the same preparation procedure. Therefore, protein farnesylation and geranylgeranylation were expressed as protein-bound farnesyl and geranylgeranyl group in $\mathrm{ng} / \mathrm{mg}$ protein.

\subsection{Measurement of myocardial cholesterol}

Tissue cholesterol was measured (Cholesterol/Cholesterol Ester Quantification kit; BioVision, Mountain View, CA) from ventricular homogenates according to the manufacturer's instructions. Ten mg ventricular homogenates were used for tissue cholesterol measurement. Myocardial cholesterol was expressed in $\mathrm{ng} / \mathrm{mg}$ protein.

\subsection{Measurement of myocardial coenzyme $Q$}

The level of cardiac coenzyme Q9 and Q10 were measured by a HPLC method following lipid extraction with n-hexane as previously described [88]. Coenzyme Q9 and Q10 were detected at $275 \mathrm{~nm}$ using an YL 9160 PDA detector following separation with a YL9100 HPLC system on a C18 column (YMC Basic, $50 \mathrm{~mm} \times 4.6 \mathrm{~mm}$ ID $3 \mu \mathrm{m}$ ). Four hundred $\mathrm{mg}$ ventricular homogenate was used for myocardial coenzyme Q measurement. Calibration curves were made using coenzyme Q9 and Q10 standards (Sigma, St. Louis, MO). Myocardial coenzyme Q9 and Q10 were expressed in ng/mg protein.

\subsection{Measurement of myocardial dolichol}

The level of cardiac dolichol was measured by HPLC method as previously described [89]. Briefly, minced cardiac tissues $(400 \mathrm{mg}$ ) were mixed with $0.5 \mathrm{ml} 0.25 \%$ pyrogallol in methanol and $0.5 \mathrm{ml} 60 \% \mathrm{KOH}$. Hydrolysis was performed in a water bath at $100^{\circ} \mathrm{C}$ for 30 min; the mixture was extracted three times with diethyl ether:petroleum ether $(1: 1)$. The pooled extracts were washed with methanol:diethyl ether (1:1) and were dried under nitrogen. The samples were resolved with isopropanol:acetonitrile (65:35). Dolichol was detected at $210 \mathrm{~nm}$ using an YL 9160 PDA detector following separation with an YL9100 HPLC system on C18 column (YMC-Pack ODS-AQ, $10 \mathrm{~mm} \times 4.0 \mathrm{~mm}$ ID $3 \mu \mathrm{m}$ and YMC-Pack ODS-AQ, $150 \mathrm{~mm} \times 4.6 \mathrm{~mm}$ ID $5 \mu \mathrm{m})$. Calibration curve was made using C90-Dolichol standard (Larodan, Malmö, Sweden). Myocardial dolichol was expressed in ng/mg protein.

\subsection{Measurement of 3-nitrotyrosine}

Cardiac free 3-nitrotyrosine content, as markers for peroxynitrite-induced oxidative/nitrosative stress, was measured after 10 minutes of perfusion. Cardiac free 3- 
nitrotyrosine level was measured by enzyme-linked immunosorbent assay (ELISA; Cayman Chemical, Ann Arbor, MI) from heart tissue samples according to the instructions. Briefly, supernatants of $50 \mathrm{mg}$ ventricular tissue homogenate was incubated overnight with antinitrotyrosine rabbit IgG specific to free 3-nitrotyrosine and nitrotyrosine acetylcholinesterase tracer in precoated (mouse anti-rabbit IgG) microplates followed by development with Ellman's reagent. Free 3-nitrotyrosine content was normalized to protein content of cardiac homogenate and expressed as ng/mg protein.

\subsection{Measurement of protein concentration}

Protein concentrations were measured by the BCA Protein Assay kit (Thermo, Rockford, IL) according to the instructions.

\subsection{Neonatal cardiomyocyte culture experiments}

In order to investigate if farnesol has a direct cardiocytoprotective effect, we investigated whether farnesol protects cardiomyocytes subjected to simulated ischemia/reperfusion. Neonatal cardiomyocyte cultures were prepared as described previously [90]. Cells were kept in normoxic incubator and supplied with proliferation medium for 1 day $(\mathrm{DMEM}+10 \%$ FBS $)$. Then farnesol $(0.0032-250 \mu \mathrm{M})$ was administered in differentiation medium (DMEM + 1\% FBS) for 2 days. After farnesol treatment, the culture medium was changed to hypoxic solution [91] and plates were placed into a hypoxic chamber, and cells were exposed to a constant flow of a mixture of $95 \% \mathrm{~N}_{2}$ and $5 \% \mathrm{CO}_{2}$ at $37{ }^{\circ} \mathrm{C}$ for $4 \mathrm{~h}$. Simulated ischemia was followed by $2 \mathrm{~h}$ simulated reperfusion using differentiation medium and normoxia (Figure 4). To assess cell viability cardiomyocytes were incubated with $1 \mu \mathrm{M}$ calcein acetoxymethyl ester (calcein-AM, Sigma, St Louis, MO) at room temperature for 30 min. Fluorescence intensity was measured with a fluorescence plate reader (Fluostar Optima, BMG Labtech, Ortenberg, Germany) at 490-nm excitation and 520-nm emission filters. Simulated ischemia/reperfusion resulted in $21 \%$ decrease in cell viability as compared to normoxia ( $4 \mathrm{~h}$ normoxia with normoxic solution followed by simulated reperfusion, data not shown). 


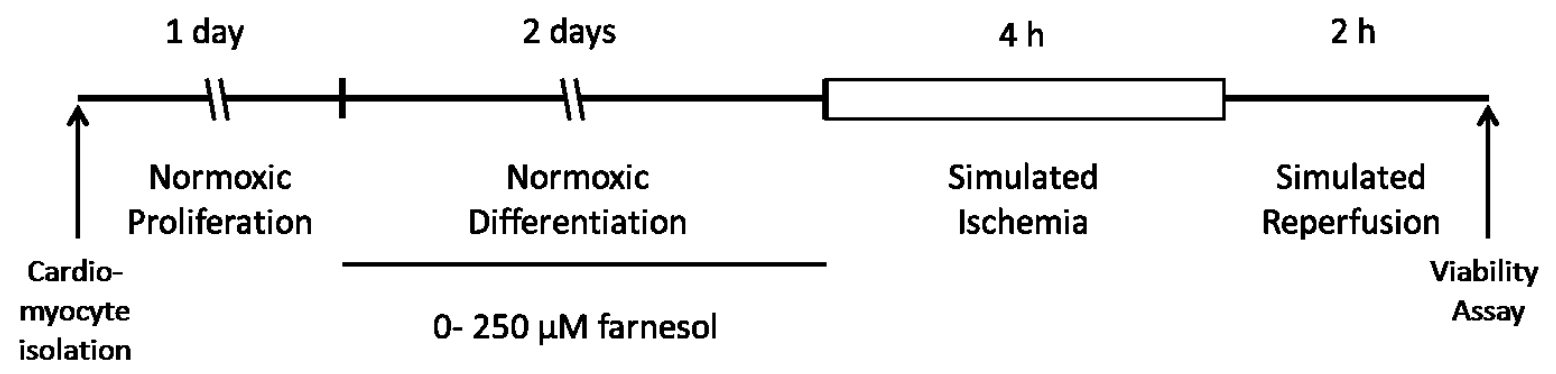

Figure 4. Experimental protocol of cardiomyocyte culture experiments. To assess the protective effect of farnesol, neonatal rat cardiomyocytes were treated with $\mathbf{0 . 0 0 3 2}$, $0.016,0.08,0.4,2,10,50$, and $250 \mu M$ farnesol or its vehicle (0.1\% DMSO), respectively. To test ischemic tolerance, cardiomyocytes were subjected $4 \mathrm{~h}$ simulated ischemia and 2 $\mathrm{h}$ simulated reperfusion. Cell viability was assessed by calcein viability assay.

\subsection{MMP2 zymography}

Coronary effluent collected for 10 minutes before ischemia and the first 10 minutes of reperfusion was concentrated by ultra-filtration using Amicon ultra filtration tubes (Millipore, Billerica, MA). The concentrated coronary flow was then subjected to gelatin zymography. Gelatinolytic activities of MMPs were examined as previously described [19]. Briefly, polyacrylamide gels were copolymerized with gelatin, and a constant amount of protein was separated by electrophoresis in each lane. Following electrophoresis, gels were washed with $2.5 \%$ Triton X-100 and incubated for 20 hours at $37^{\circ} \mathrm{C}$ in incubation buffer. Gels were then stained with $0.05 \%$ Coomassie Brilliant Blue in a mixture of methanol/acetic acid/water and destained in aqueous $4 \%$ methanol $/ 8 \%$ acetic acid. Zymograms were digitally scanned, and band intensities were quantified using Quantity One software (Bio-Rad, Hercules, CA) and expressed as a ratio to the internal standard.

\subsection{Serum cholesterol and triglyceride measurement}

Serum cholesterol and triglyceride were measured using a test kit supplied by Diagnosticum Zrt. (Budapest, Hungary) as described previously [20].

\subsection{Statistics}

All values are presented as mean \pm SEM. Differences among means were analyzed by Student's unpaired t-test or one-way ANOVA followed by an appropriate post hoc test, respectively. All comparisons were made versus the vehicle-treated or vehicle-treated 
ischemia/reperfusion group or corresponding control group. Statistical significance was defined as $p<0.05$. 


\section{RESULTS}

\subsection{Study 1}

\subsubsection{Infarct size}

To assess the cardioprotective effect of different oral doses of farnesol, infarct size was measured after $30 \mathrm{~min}$ regional ischemia and $120 \mathrm{~min}$ of reperfusion. Infarct size was significantly decreased by $1 \mathrm{mg} / \mathrm{kg} /$ day farnesol $(22.3 \pm 3.9 \%$ vs. $40.9 \pm 6.1 \%, \mathrm{p}<0.05$, Figure 5). However, $0.2,5$, and $50 \mathrm{mg} / \mathrm{kg} /$ day farnesol treatment did not significantly decrease infarct size $(37.3 \pm 5.1 \%, 32.0 \pm 3.1 \%, 43.5 \pm 5.1 \%$ vs. $40.9 \pm 6.1 \%$, respectively, Figure 5). Therefore, the infarct size reducing effect of farnesol showed a U-shaped dose-response relationship. Farnesol did not affect body weight, heart weight, coronary flow and heart rate (Table 1).

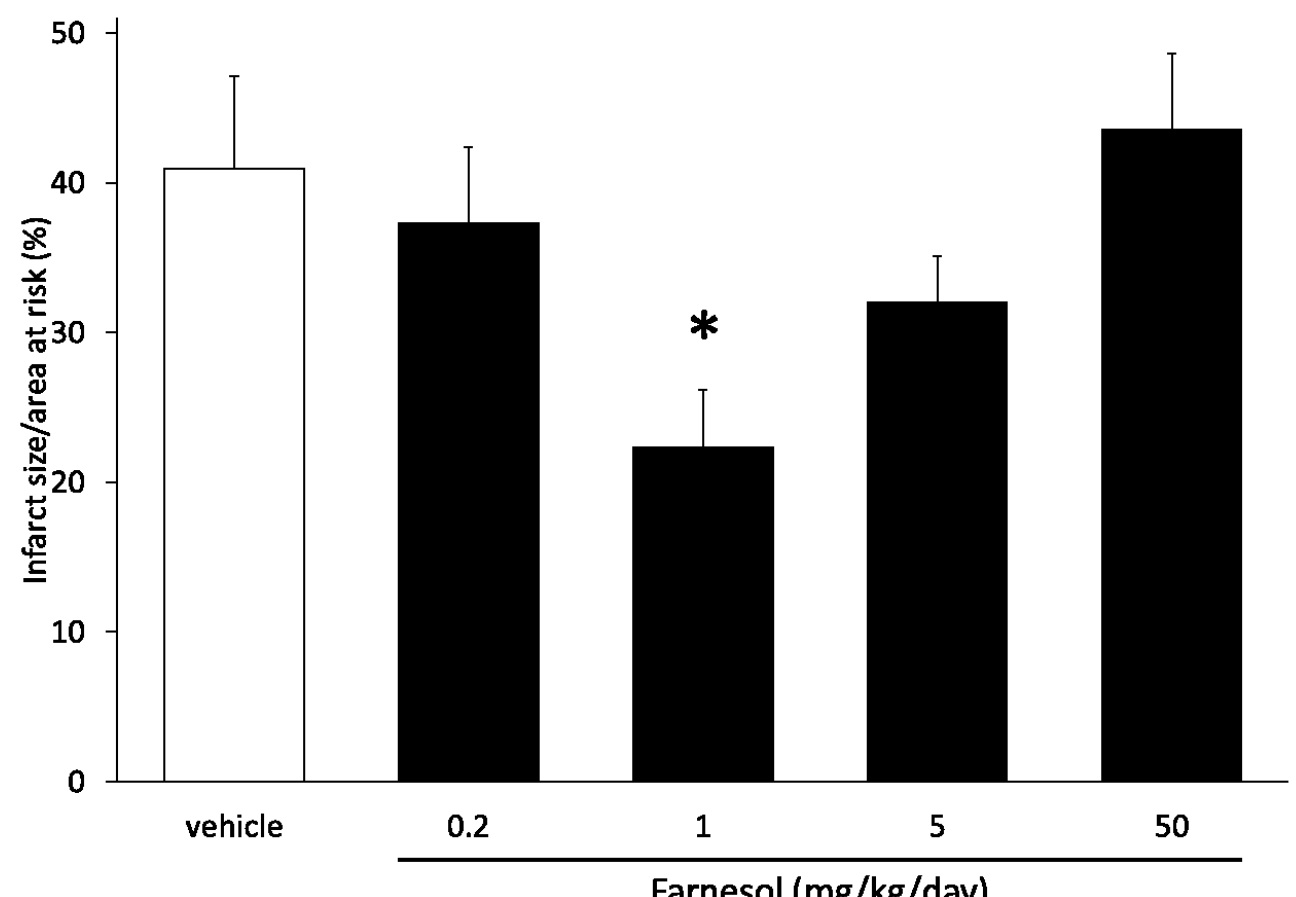

Figure 5. Effect of farnesol on myocardial infarct size. Infarct size is expressed as a percentage of the area at risk of isolated hearts that was subjected to 12 days vehicle or $0.2,1,5$, and $50 \mathrm{mg} / \mathrm{kg} / \mathrm{day}$ farnesol treatment followed by $30 \mathrm{~min}$ coronary occlusion followed by $120 \mathrm{~min}$ reperfusion to measure infarct size. Values are mean $\pm S E M ; n=8$ 13 in each group; *p $<0.05$ vs. vehicle. 


\begin{tabular}{lccccc}
\hline Farnesol (mg) & vehicle & 0.2 & 1 & 5 & 50 \\
\hline Body weight (g) & $350 \pm 5(34)$ & $337 \pm 8(8)$ & $353 \pm 5(32)$ & $334 \pm 3(14)$ & $361 \pm 6(20)$ \\
Heart weight (g) & $1.28 \pm 0.02(34)$ & $1.27 \pm 0.06(8)$ & $1.30 \pm 0.03(32)$ & $1.21 \pm 0.04(14)$ & $1.27 \pm 0.04(20)$ \\
Area at risk (\%) & $54.9 \pm 3.2(10)$ & $43.7 \pm 4.4(8)$ & $46.2 \pm 4.6(11)$ & $64.9 \pm 3.6(12)$ & $50.1 \pm 2.6(13)$ \\
Coronary flow (mL/min) & & & & \\
Before isch & $17.9 \pm 0.5(33)$ & $17.2 \pm 1.6(8)$ & $18.0 \pm 0.6(32)$ & $16.6 \pm 0.7(14)$ & $16.9 \pm 1.1(18)$ \\
During isch & $10.1 \pm 1.1(11)$ & $9.3 \pm 1.0(8)$ & $9.8 \pm 0.5(12)$ & $10.1 \pm 0.8(12)$ & $9.0 \pm 0.7(13)$ \\
0-5 min of rep & $88.0 \pm 6.2(11)$ & $72.6 \pm 5.3(8)$ & $82.8 \pm 6.6(12)$ & $88.0 \pm 7.7(12)$ & $75.1 \pm 4.0(13)$ \\
End of rep & $12.6 \pm 1.3(11)$ & $11.5 \pm 1.4(8)$ & $14.4 \pm 1.1(12)$ & $14.3 \pm 1.5(12)$ & $11.6 \pm 0.8(13)$ \\
Heart rate (beats/min) & & & & \\
Before isch & $284 \pm 18(14)$ & $270 \pm 24(8)$ & $284 \pm 17(12)$ & $277 \pm 24(13)$ & $303 \pm 9(13)$ \\
End of isch & $250 \pm 27(7)$ & $275 \pm 35(8)$ & $288 \pm 28(11)$ & $292 \pm 31(11)$ & $308 \pm 19(7)$ \\
End of rep & $288 \pm 9(6)$ & $279 \pm 23(7)$ & $239 \pm 28(8)$ & $259 \pm 35(8)$ & $294 \pm 17(8)$
\end{tabular}

Table 1. Body weight, animal weight, area at risk and cardiac functional parameters in vehicle or $0.2,1,5$, and $50 \mathrm{mg} / \mathrm{kg} /$ day farnesol-treated groups for 12 days followed by either 10 min of aerobic perfusion for tissue sampling or $30 \mathrm{~min}$ coronary occlusion followed by 120 min reperfusion to measure infarct size. Body weight, heart weight, and coronary flow before ischemia were measured from all animals served for infarct size measurement and assessment of biochemical parameters to yield sample size $n=6-34$ in different groups. Values are mean $\pm \operatorname{SEM}(n)$.

\subsubsection{Mevalonate pathway end-products}

In separate sets of experiments, to assess the effect of cardioprotective $(1 \mathrm{mg} / \mathrm{kg} / \mathrm{day})$ dose of farnesol on mevalonate pathway end-products, we measured cardiac protein prenylation, cholesterol, coenzyme Q, and dolichol. We found that oral farnesol treatment significantly increased cardiac protein-bound geranylgeranyl level $(8.4 \pm 0.9$ vs. $5.5 \pm 0.8$ $\mathrm{ng} / \mathrm{mg}$ protein, $\mathrm{p}<0.05$ ) (Figure 6). However, farnesol did not influence cardiac protein-bound 
farnesyl level (1.6 \pm 0.2 vs. $2.7 \pm 0.5 \mathrm{ng} / \mathrm{mg}$ protein), cardiac cholesterol (100.4 \pm 4.5 vs. $88.8 \pm 7.8 \mathrm{ng} / \mathrm{mg}$ protein), coenzyme Q9 and Q10 (13.1 \pm 0.7 vs. $11.0 \pm 2.8 \mathrm{ng} / \mathrm{mg}$ protein and $0.89 \pm 0.06$ vs. $0.74 \pm 0.19 \mathrm{ng} / \mathrm{mg}$ protein, respectively), and dolichol levels significantly (0.32 \pm 0.03 vs. $0.37 \pm 0.03 \mathrm{ng} / \mathrm{mg}$ protein) (Figure 6).

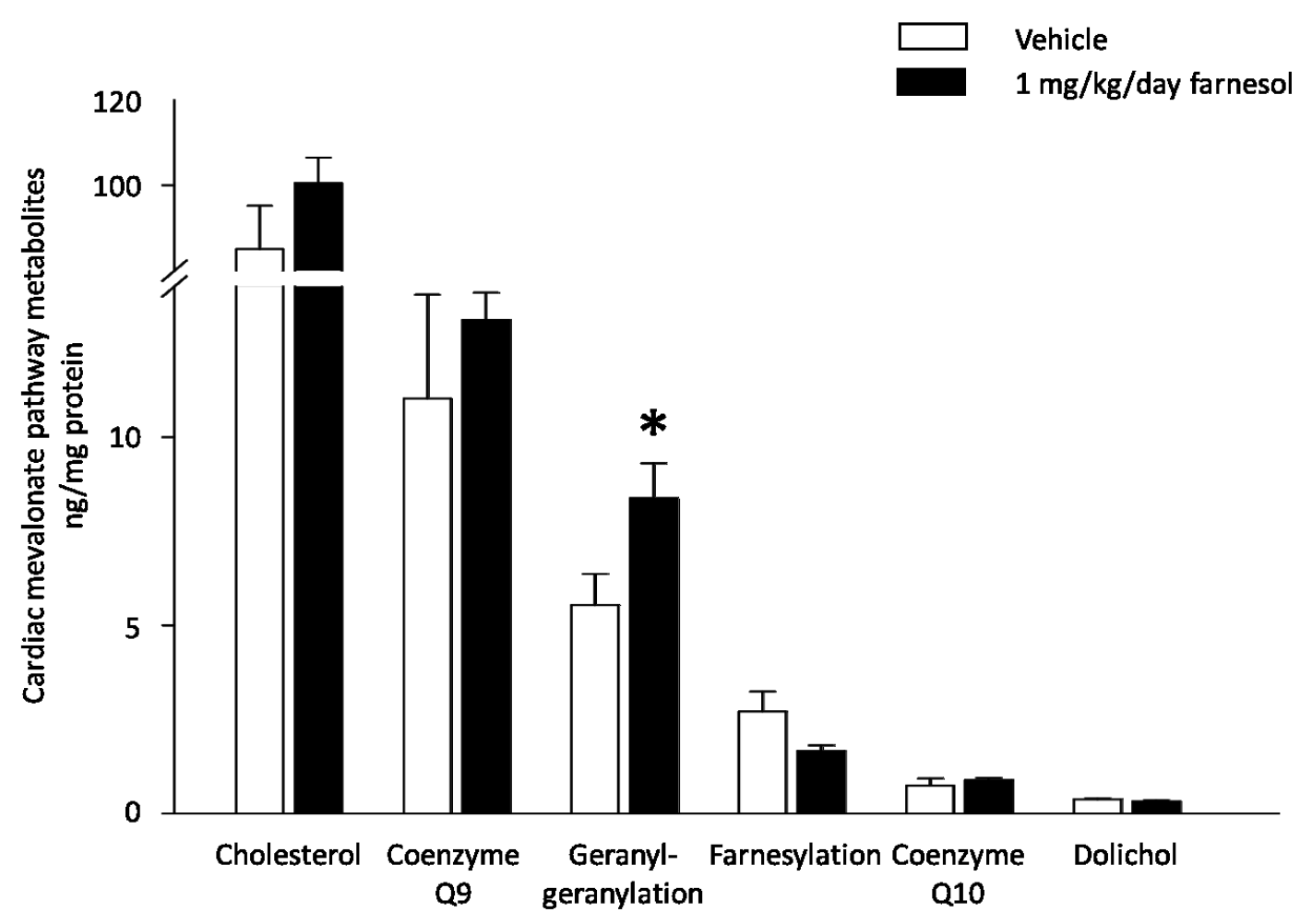

Figure 6. Cardiac mevalonate pathway metabolites (cardiac cholesterol, coenzyme Q10, protein geranylgeranylation, protein farnesylation, coenzyme Q9, and dolichol) from rats orally treated with vehicle or $0.2,1,5$, and $50 \mathrm{mg} / \mathrm{kg} /$ day farnesol for 12 days. Values are mean $\pm S E M ; n=6-8$ in each group. ${ }^{*} p<0.05$ vs. vehicle.

\subsubsection{3-nitrotyrosine}

To assess the antioxidant effect of the cardioprotective dose of farnesol in the heart, in separate experiments, we measured cardiac 3-nitrotyrosine level as marker of cardiac peroxynitrite which is a major player in cardiac oxidative and nitrosative stress. We found that the cardioprotective dose of farnesol ( $1 \mathrm{mg} / \mathrm{kg} /$ day $)$ did not affect cardiac 3-nitrotyrosine level (Figure 7). Therefore, to further assess if farnesol at a higher dose may show an antioxidant effect, in separate experiment, we measured 3-nitrotyrosine in the $50 \mathrm{mg} / \mathrm{kg} /$ day farnesoltreated group. This dose of farnesol $(50 \mathrm{mg} / \mathrm{kg} /$ day $)$ significantly decreased cardiac 3- 
nitrotyrosine level ( $1.2 \pm 0.2$ vs. $2.4 \pm 0.5 \mathrm{ng} / \mathrm{mg}$ protein, $\mathrm{p}<0.05)$ (Figure 7), however, it did not show any cardioprotective effect (see above, Figure 5).

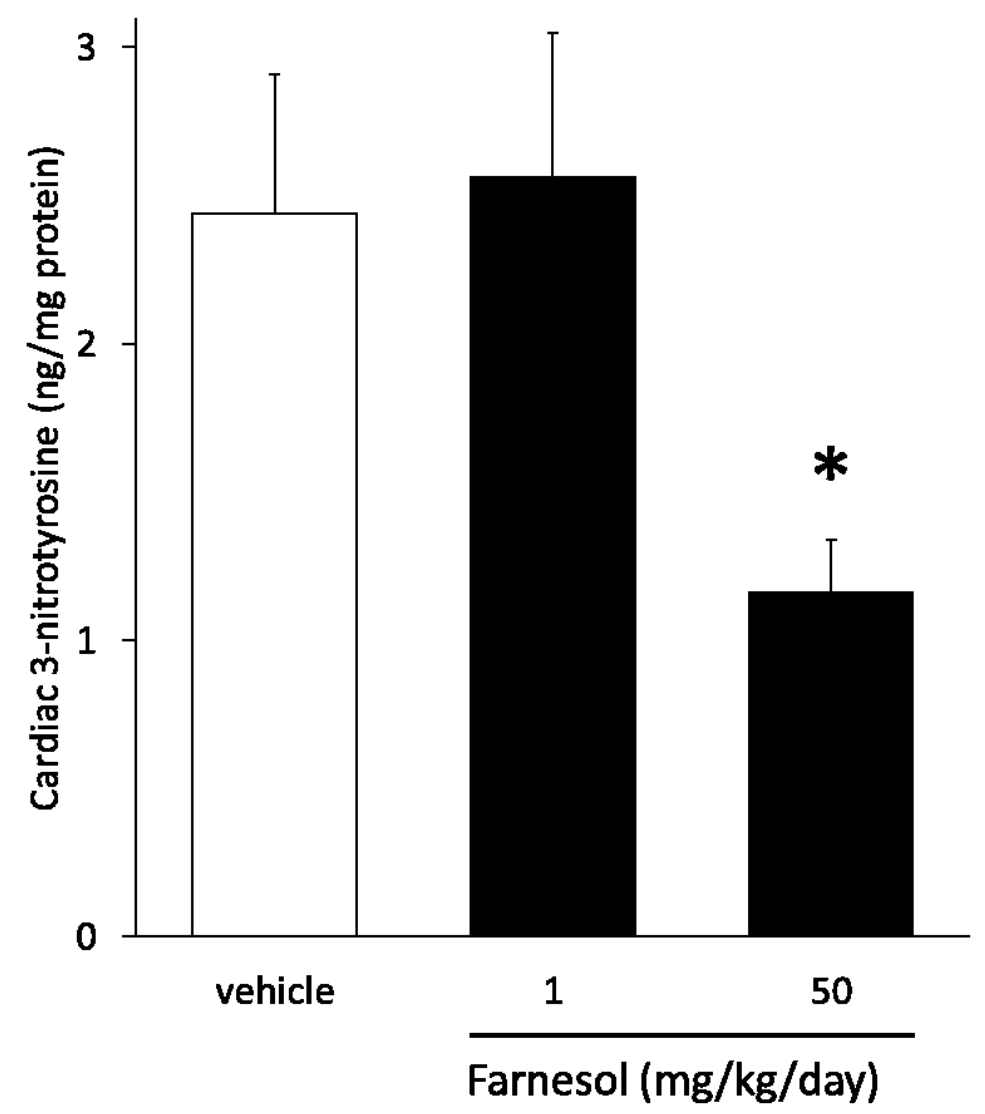

Figure 7. Cardiac 3-nitrotyrosine from rats oral treated with vehicle or 1 and 50 $\mathrm{mg} / \mathrm{kg} / \mathrm{day}$ farnesol for 12 days. Values are mean $\pm \mathrm{SEM} ; \mathrm{n}=7$ in each group, $* \mathbf{p}<0.05$ vs. vehicle.

\subsubsection{Cardiomyocyte culture results}

To assess if farnesol has a direct cardiocytoprotective effect, we measured cell viability of cardiomyocytes subjected to simulated ischemia/reperfusion. Farnesol (0.0032 $50 \mu \mathrm{M})$ protected cardiomyocytes in a bell-shaped concentration-response manner similarly to that observed in the isolated heart experiments $(0.016 \mu \mathrm{M}$ farnesol: $40.4 \pm 1.4 \mathrm{AU}, 0.08 \mu \mathrm{M}$

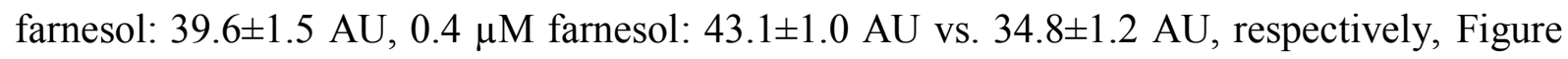
8). However, $250 \mu \mathrm{M}$ farnesol showed a cytotoxic effect (data not shown). 


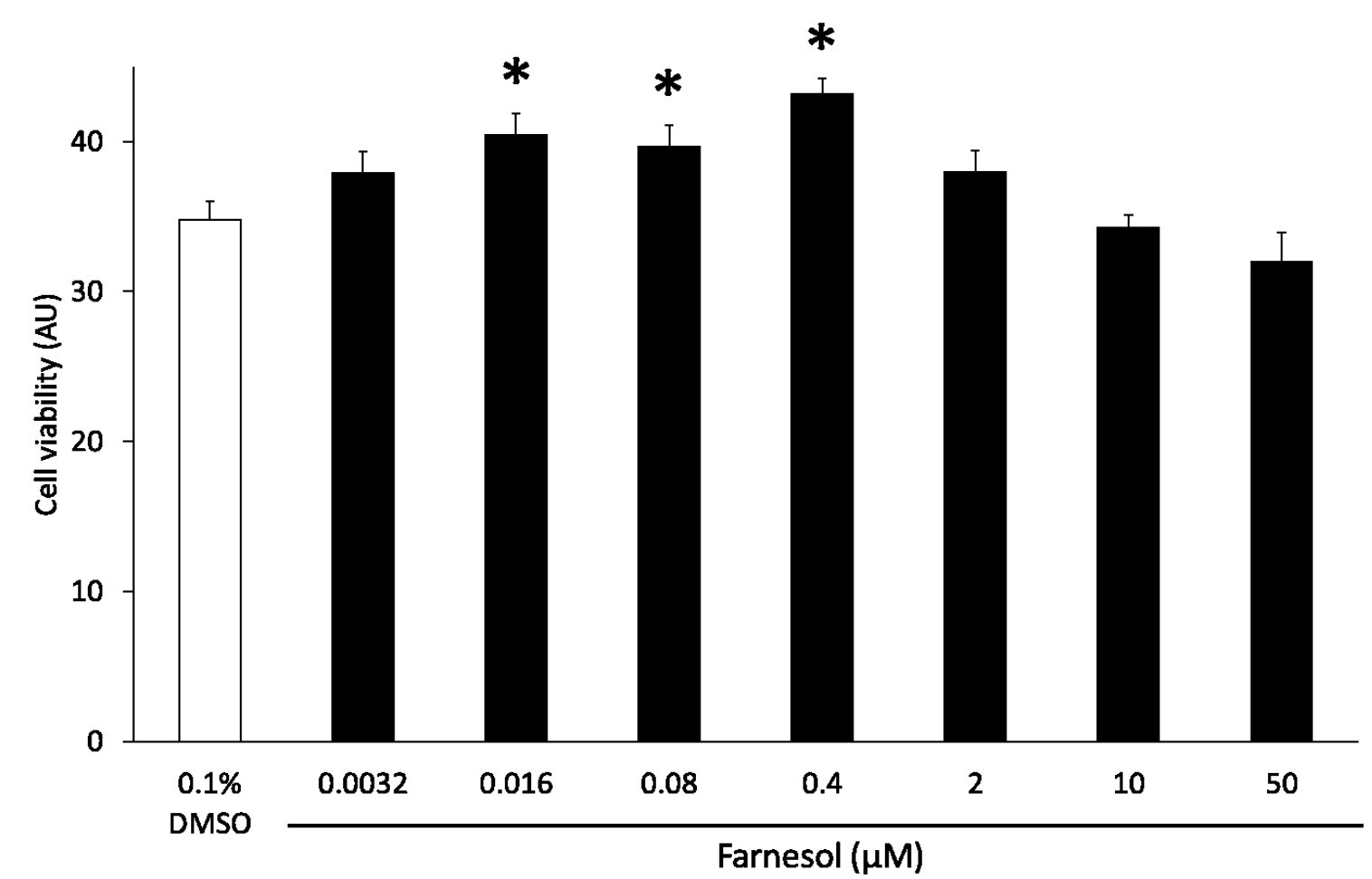

Figure 8. Viability assay for neonatal rat cardiomyocytes treated with $0.0032,0.016$, $0.08,0.4,2,10$, and $50 \mu \mathrm{M}$ farnesol or its vehicle (0.1\% DMSO), respectively for 2 days. Values are mean \pm SEM; $n=16-24$ well. * $p<0.05$ vs. vehicle.

\subsection{Study 2}

\subsubsection{Animal mass}

The body and heart weight of the RPO supplemented rats were significantly decreased when compared to the Norm group and also to the Chol+RPO group after the feeding period (Table 2).

\begin{tabular}{ccccc}
\hline & Norm & Chol & Norm+RPO & Chol+RPO \\
\hline Animal mass (g) & $494.0 \pm 18.1$ & $472.6 \pm 13.5$ & $381.3 \pm 7.6^{*}$ & $511.5 \pm 14.4$ \\
Heart mass (g) & $1.6 \pm 0.1$ & $1.7 \pm 0.1$ & $1.4 \pm 0.1^{*}$ & $1.7 \pm 0.1$ \\
\hline
\end{tabular}

Table 2. Animal mass and heart mass after a nine week diet. Values are mean \pm SEM, $n$ $=8 ; * \mathbf{p}<0.05$ versus Norm and Chol+RPO. 


\subsubsection{Perfusion data}

There were no significant differences in the coronary effluent of any of the groups after the supplementation period. Coronary effluent of all groups except the RPO group was significantly decreased after ischemia, when compared to their baseline values. There were no significant differences in the heart rates before or after ischemia (Table 3).

\begin{tabular}{lcccc}
\hline & $\begin{array}{c}\text { CE before } \\
\text { ischemia } \\
(\mathrm{mL} / 10 \mathrm{~min})\end{array}$ & $\begin{array}{c}\text { CE after } \\
\text { ischemia } \\
(\mathrm{mL} / 10 \mathrm{~min})\end{array}$ & $\begin{array}{c}\text { HR before } \\
\text { ischemia } \\
(\mathrm{BPM})\end{array}$ & $\begin{array}{c}\text { HR after } \\
\text { ischemia } \\
(\mathrm{BPM})\end{array}$ \\
\hline Norm & $205.0 \pm 5.7$ & $59.2 \pm 4.0^{*}$ & $387.4 \pm 56.5$ & $338.0 \pm 128.6$ \\
Chol & $185.9 \pm 21.7$ & $67.1 \pm 6.5^{*}$ & $390.8 \pm 37.3$ & $346.0 \pm 115.3$ \\
Norm+RPO & $152.5 \pm 12.9$ & $100.0 \pm 6.9$ & $344.1 \pm 12.0$ & $328.0 \pm 40.7$ \\
Chol+RPO & $141.9 \pm 12.5$ & $61.9 \pm 3.8^{*}$ & $327.3 \pm 17.6$ & $339.0 \pm 29.2$
\end{tabular}

Table 3. Coronary effluent (CE) collected for $10 \mathrm{~min}$ to measure MMP activity and heart rate (HR) before and after ischemia. Values are mean $\pm \mathrm{SEM}, \mathbf{n}=\mathbf{8} ;{ }^{*} \mathbf{p}<0.05$ versus the corresponding "before ischemia" values.

\subsubsection{Infarct size}

Cholesterol-enriched diet alone increased myocardial infarct size from $23.5 \pm 3.0 \%$ to $37.2 \pm 3.6 \%(\mathrm{p}<0.05)$ when compared to normal diet. RPO supplementation significantly reduced infarct size in Norm+RPO and also in Chol+RPO $(9.2 \pm 1.0 \%$ and $26.9 \pm 3.0 \%)$, respectively (Figure 9). Infarct size in Chol+RPO group was comparable to the group fed with normal diet.

\subsubsection{MMP2}

Before ischemia activity of the $75 \mathrm{kDa}$ isoform of MMP2 was significantly lower in the Chol+RPO group when compared to the Chol group (228 \pm 28 AU versus $450 \pm 34 \mathrm{AU}$; (Figure 10). After ischemia MMP2 (72kDa isoform) activity of the RPO supplemented group was significantly increased when compared to rats with normal diet $(2472 \pm 132$ AU versus $2007 \pm 68$ AU; Figure 11). 


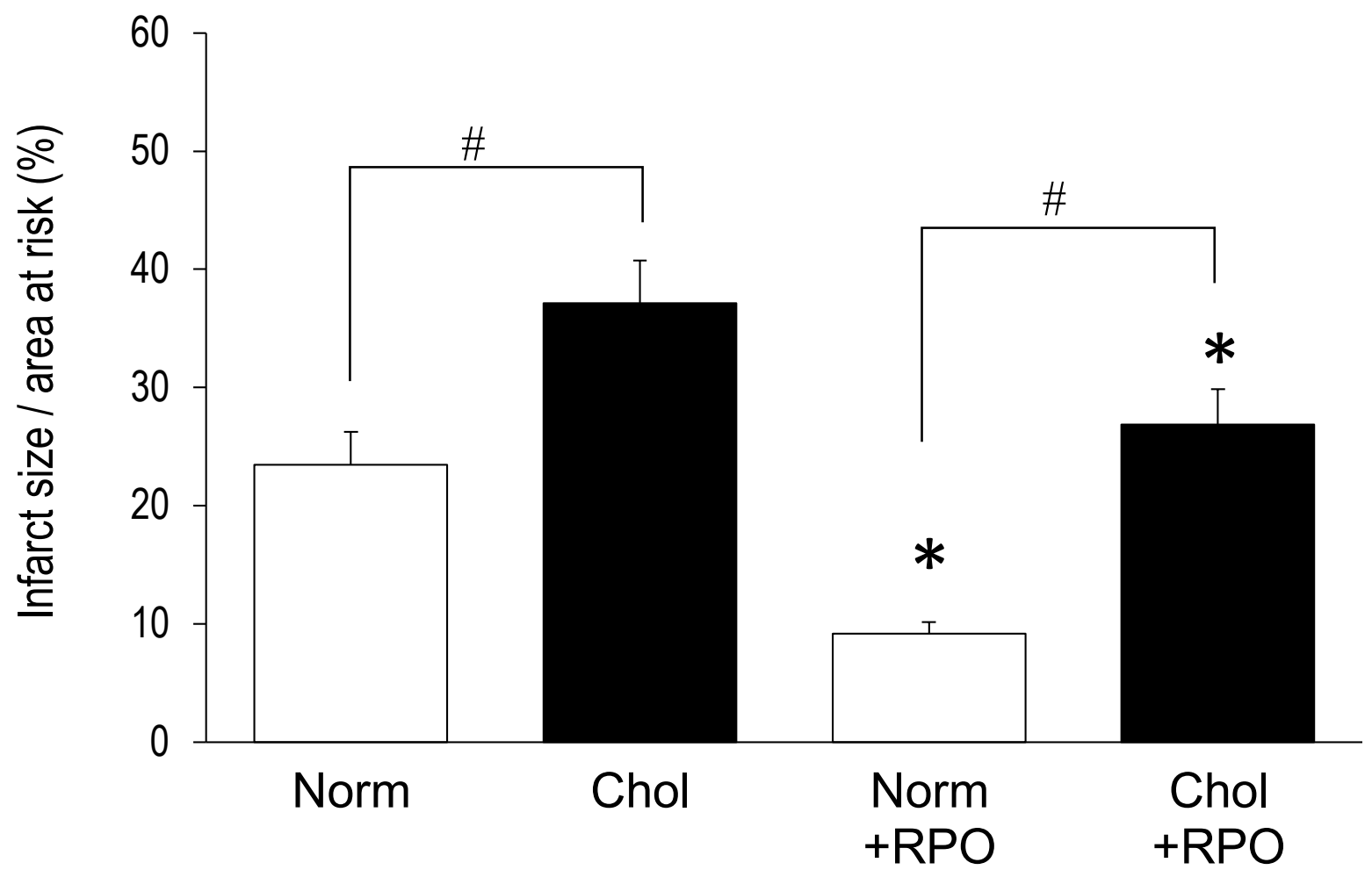

Figure 9. Myocardial infarct size in rats fed different diets for nine weeks. Infarct size is expressed as a percentage of the area at risk, values are mean $\pm S E M, n=8 ; * p<0.05$ versus corresponding non-RPO treated groups; \#p $<0.05$ versus corresponding normal diet.

\subsubsection{Serum lipid profile}

There were no significant differences in the serum total cholesterol and triglyceride level among groups (Table 4).

\begin{tabular}{ccccc}
\hline & Norm & Chol & Norm+RPO & Chol+RPO \\
\hline $\begin{array}{c}\text { Total cholesterol } \\
(\text { mmol } / \mathrm{L})\end{array}$ & $1.96 \pm 0.05$ & $1.91 \pm 0.05$ & $2.15 \pm 0.23$ & $1.79 \pm 0.04$ \\
$\begin{array}{c}\text { Triglycerides } \\
(\mathrm{mmol} / \mathrm{L})\end{array}$ & $0.72 \pm 0.06$ & $0.80 \pm 0.08$ & $0.71 \pm 0.06$ & $0.80 \pm 0.07$ \\
\hline
\end{tabular}

Table 4. Serum total cholesterol and serum triglyceride levels of rats after nine weeks of diet. Values are mean $\pm S E M, n=8$. 

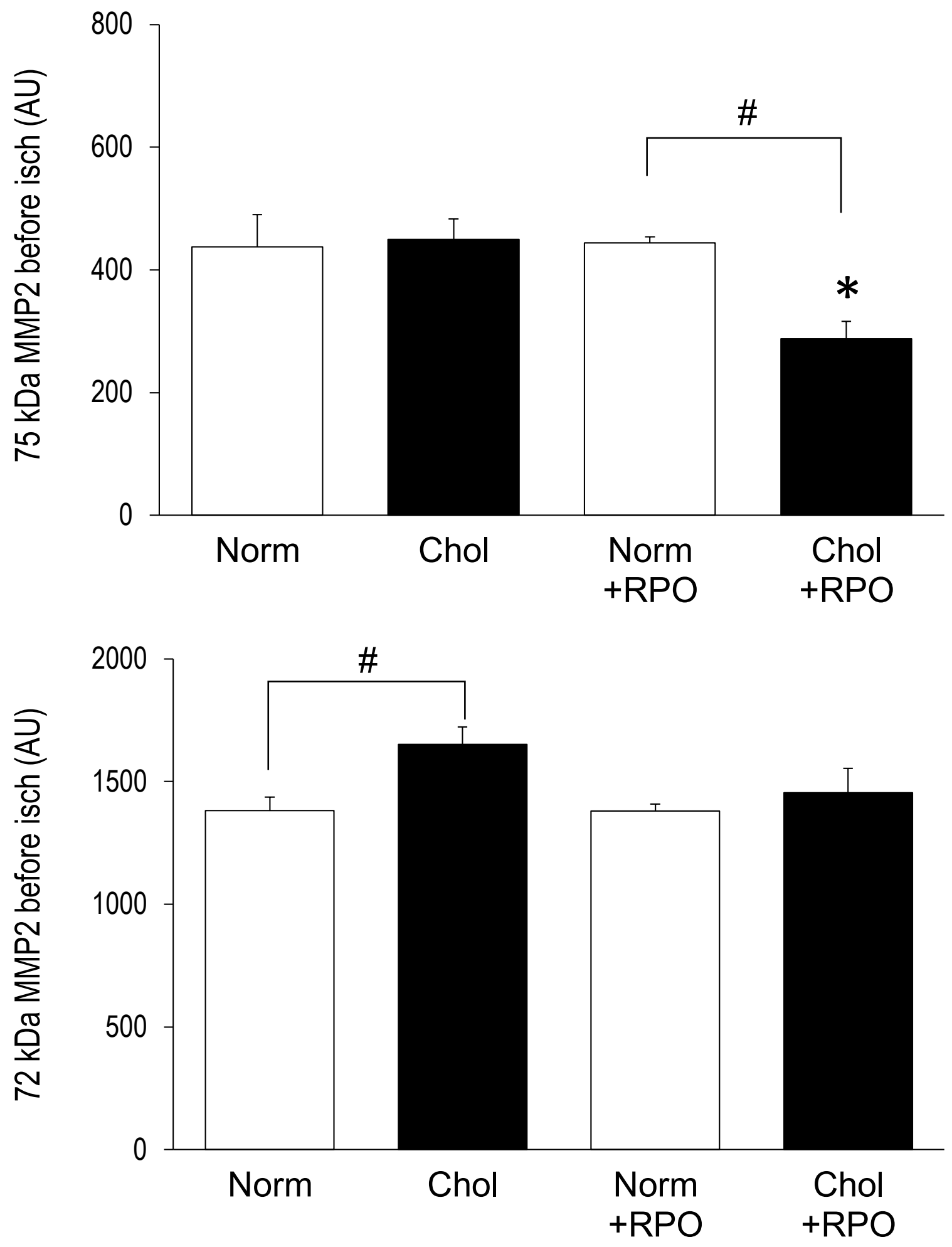

Figure 10. MMP2 activity in coronary effluent collected for 10 minutes before ischemia. Values are mean $\pm \mathrm{SEM}, \mathbf{n}=\mathbf{8} ; * \mathbf{p}<\mathbf{0 . 0 5}$ versus corresponding non-RPO treated groups; $\# p<0.05$ versus corresponding normal diet. 

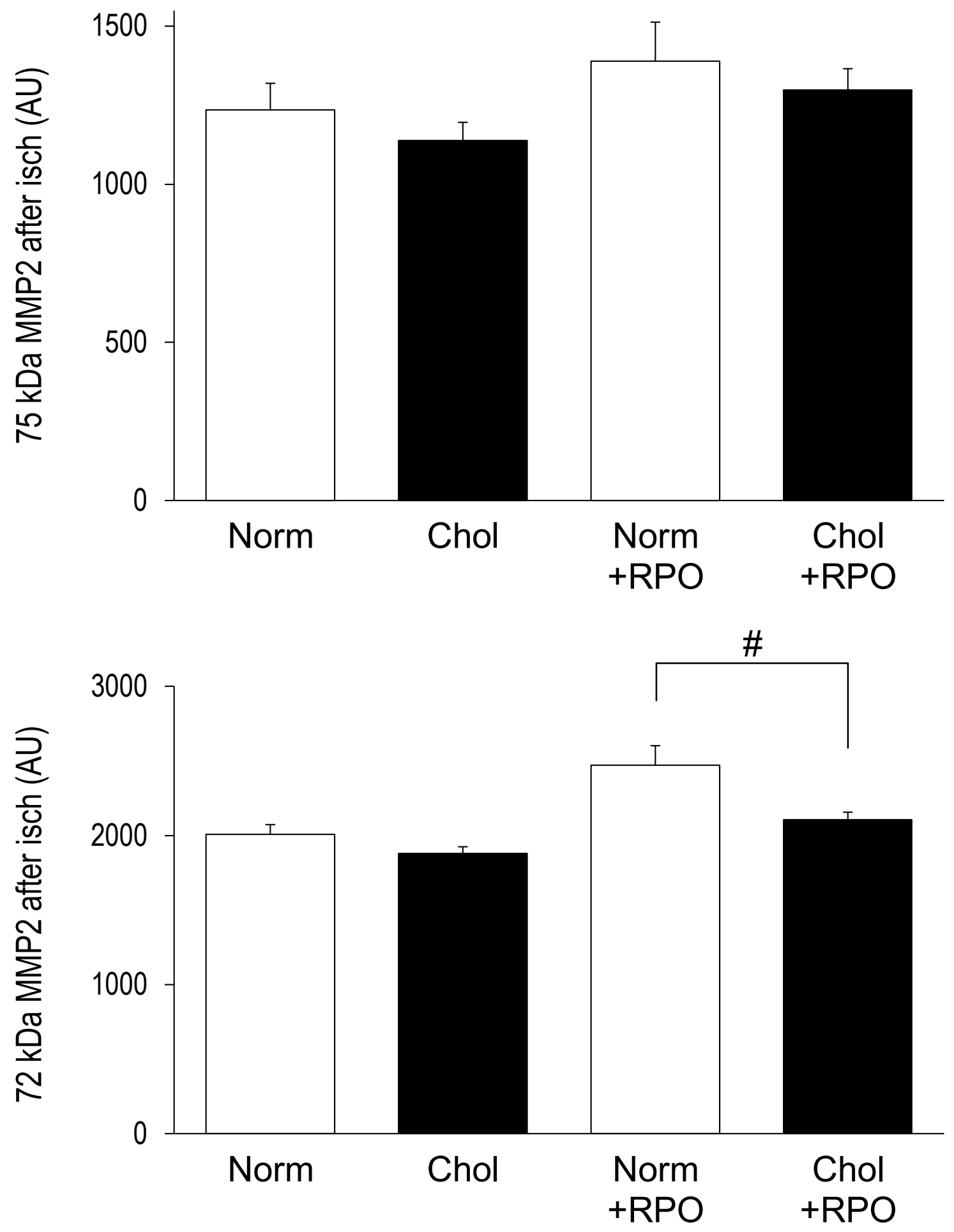

Figure 11. MMP2 activity in coronary effluent collected for the first $\mathbf{1 0}$ minutes of reperfusion. Values are mean $\pm \mathrm{SEM}, \mathrm{n}=\mathbf{8} ;{ }^{*} \mathbf{p}<0.05$ versus corresponding non-RPO treated groups; $\# \mathbf{p}<\mathbf{0 . 0 5}$ versus corresponding normal diet. 


\section{DISCUSSION}

\subsection{Study 1}

This is the first demonstration that oral farnesol treatment reduces infarct size in the rat heart following ischemia/reperfusion. We also found that farnesol shows a direct cytoprotective effect in cardiomyocytes subjected to simulated ischemia/reperfusion. Furthermore, we found that the in-vivo cardioprotective dose of farnesol $(1 \mathrm{mg} / \mathrm{kg} /$ day for 12 days) increased the geranylgeranylation of cardiac proteins, however, it did not affect other mevalonate pathway-derived end-products (cardiac cholesterol, coenzyme Q, dolichol) and cardiac peroxynitrite marker 3-nitrotyrosine level significantly. This shows that the cardioprotective effect of farnesol is independent of its antioxidant effect but may involve changes in protein geranylgeranylation (Figure 12).

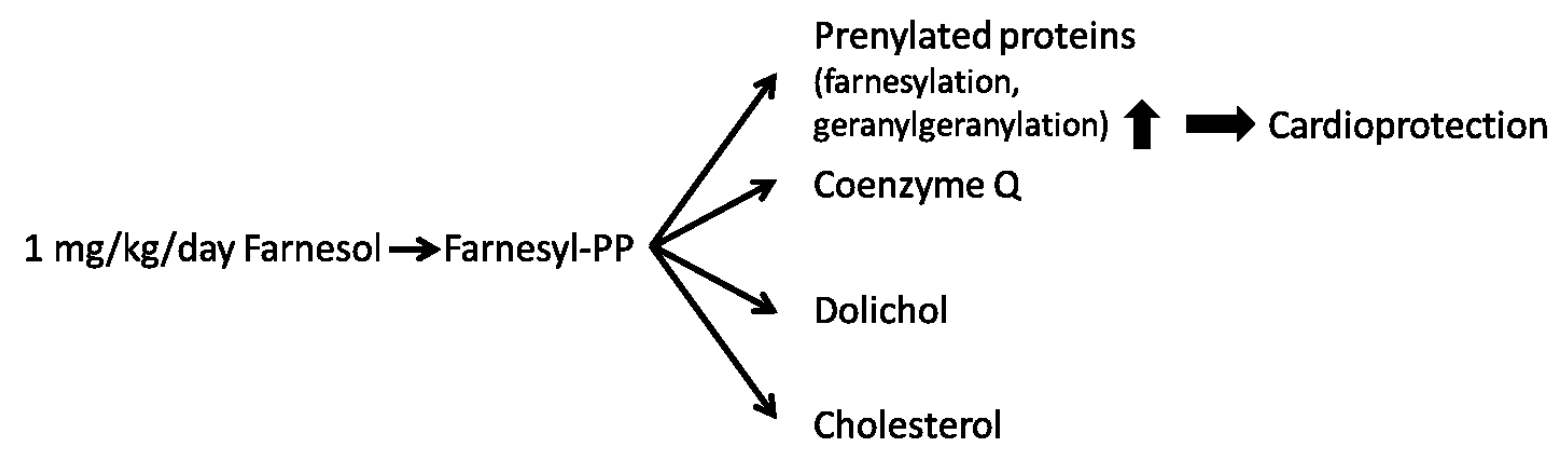

Figure 12. Proposed mechanism of cardioprotection by farnesol.

It is known that mammalian cells can utilize farnesol for protein prenylation [34] and for synthesis of other mevalonate pathway derivatives (cholesterol, coenzyme Q, and dolichol) [34] (Figure 1). Bentinger et al. (1998) has shown in rats that farnesol could be phosphorylated in vivo to form farnesyl-pyrophosphate, which could re-enter biosynthetic reactions [33]. Our present results support this finding since administration of exogenous farnesol increased total myocardial protein geranylgeranylation and reduced infarct size.

Prenylation (protein farnesylation and geranylgeranylation) is a lipid post-translational modification of proteins involving the irreversible covalent attachment of either farnesyl (15carbon) or geranylgeranyl (20-carbon) isoprenoid to conserved cysteine residues at or near the C-terminus of numerous cellular proteins [92]. Prenyl groups act as hydrophobic membrane anchors [40] and play key role in the maturation of proteins [41], regulation of protein 
targeting, function of proteins, and controlling apoptosis [40,93]. Large number of proteins is known to be prenylated, such as e.g. $\gamma$ subunit of heterotrimeric G-proteins, nuclear lamins, and some members of the Ras superfamily of small GTPases e.g.: Ras, Rho, Rac, Rab subfamily [40-42]. Some of these proteins have been shown to be involved in cardioprotection. Brar et al. (2004) also showed that cardioprotective effect of urocortin-II against ischemia/reperfusion injury in rat heart was completely abolished by the Ras inhibitor manumycin A [94]. It was also shown that infarct size was increased in cardiac specific RhoA knockout mice hearts and was significantly decreased in cardiac-specific RhoA transgenic mice [95]. It was also reported that activation of c-Jun N-terminal kinase through the Rac1/cdc42-TAK-1 pathway promotes survival of cardiac myocytes after hypoxiareoxygenation [96]. Members of the Rab subfamily are geranylgeranylated [40] while the other small GTPases either farnesylated or geranylgeranylated [93]. In our present study, we measured total protein farnesylation and geranylgeranylation and found that farnesol treatment significantly increased total myocardial protein geranylgeranylation but not farnesylation. However, the reason for the discrepancy between farnesol-induced protein geranylgeranylation and farnesylation remained unknown and it was not investigated in our present study. Protein prenylation is catalysed by prenyl transferase enzymes, which can be classified into two main functional classes: (i) the CAAX prenyl transferases including farnesyl transferase and geranylgeranyl transferase type 1, [93], and (ii) the Rab geranylgeranyl transferase (geranylgeranyl transferase type 2) [40]. CAAX prenyltransferase activities are highly selective for their isoprenoid diphosphate substrates: farnesyl transferase for farnesyl-pyrophosphate and geranylgeranyl transferase type 1 for geranylgeranylpyrophosphate. However, farnesyl transferase can also bind geranylgeranyl-pyrophosphate with low affinity, yet the enzyme is unable to transfer the geranylgeranyl group to substrate proteins, indicating that geranylgeranyl-pyrophosphate is a competitive inhibitor of farnesyl transferase [93]. This might explain our findings regarding the difference between farnesolinduced protein geranylgeranylation and farnesylation.

Farnesyl-pyrophosphate can be utilized for synthesis of cholesterol, coenzyme Q, and dolichol [26]. In our present study, we have observed that cardiac tissue cholesterol content expressed in $\mathrm{ng} / \mathrm{mg}$ protein was approximately 10-fold higher than the level of geranylgeranyl group of protein; however, farnesol treatment did not modify cardiac cholesterol production. 
In our present study, we have found that the cardiac tissue content of coenzyme Q9 was comparable to that of protein-bound geranylgeranyl group. Cardiac level of coenzyme Q10 content was approximately 10-fold less than coenzyme Q9 or protein-bound geranylgeranyl group. Our result is in concordance with the findings of Matejíková et al. (2008) who reported that the rat heart contains approximately 10-fold more coenzyme Q9 than coenzyme Q10 [97]. Coenzyme Q is a well-known antioxidant and cardioprotective molecule $[44,98]$. In our present study, farnesol treatment failed to alter coenzyme Q levels, which suggest that farnesol-induced cardioprotection is independent of changes in coenzyme Q levels. In our experiment the dolichol content of cardiac tissue did not change, but it was 10-fold lower than protein-bound geranylgeranyl content. The role of dolichol in ischemia/reperfusion is not known in the literature. However, it was shown that dolichol kinase deficiency causes congenital dilated cardiomyopathy in patients [99,100].

Farnesol has been shown to exert antioxidant effect in vivo [36-38]. However, in our present study the cardioprotective dose of farnesol $(1 \mathrm{mg} / \mathrm{kg} /$ day $)$ failed to decrease peroxynitrite formation, a major player in oxidative/nitrosative stress. However, $50 \mathrm{mg} / \mathrm{kg} /$ day farnesol, which did not show any cardioprotective effect, significantly decreased 3-nitrotyrosine a marker of peroxynitrite, demonstrating an antioxidant effect of farnesol. These results show that the cardioprotective effect of farnesol is independent from its antioxidant effect.

We have found here that oral farnesol reduced infarct size in a $U$ shaped dosedependent manner showing the maximum efficacy at $1 \mathrm{mg} / \mathrm{kg} /$ day dose. Moreover, here we also demonstrated that farnesol exerts a similar concentration-dependent direct cytoprotective effect in cardiomyocytes in vitro. These results show that the cardioprotective effect of farnesol is not dependent on any systemic effect; however, it might be based on a direct cardiocytoprotective action. The reason for the inefficiency of higher farnesol doses (5 and $50 \mathrm{mg} / \mathrm{kg} /$ day in in-vivo experiments and 2, 10, 50, 250 $\mu \mathrm{M}$ in neonatal rat cardiomyocyte experiments) has not been revealed in this study. However, one may speculate that the potential pro-apoptotic effect of farnesol may interfere with its cardioprotective effect at higher doses. Indeed, Chagas et al. (2009) found in a partial hepatectomy model that farnesol (250 mg/kg for 2 consecutive weeks) induced apoptosis in rat hepatocytes [101]. Joo et al. (2007) reported that $250 \mu \mathrm{M}$ farnesol induced apoptosis in human lung carcinoma cell line 
[102]. Indeed, we have found here that $250 \mu \mathrm{M}$ farnesol radically decreased the viability of cardiomyocytes.

The present study has clearly shown the cardioprotective effect of farnesol and revealed several aspect of its mechanism; however its cellular mechanism has not been fully explored. An obvious limitation of the present study is that total protein farnesylation and geranylgeranylation were measured and individual protein prenylation was not examined. Further studies are necessary to identify the specific geranylgeranylated proteins, which may play a role in the cardioprotective effect of farnesol.

\subsection{Study 2}

Our results show that dietary RPO supplementation reversed the negative effects of cholesterol supplementation in the ischemia/reperfusion rat heart model. Furthermore, dietary RPO supplementation reduced myocardial infarct size in cholesterol supplemented rats. Previous studies have shown that dietary RPO supplementation improved functional recovery of cholesterol fed rats after ischemia [56,58]. In the present study cholesterol supplementation was carried out for a longer period (nine weeks versus six weeks in previous studies). This indicates that RPO could effectively protect hearts against ischemia/reperfusion injury, despite a longer duration of cholesterol feeding. Osipov and co-workers (2009) found that hypercholesterolemic pigs had increased left ventricular function throughout the ischemia/reperfusion period when compared to normal pigs [17]. This was, however, associated with an increased infarct size and increased apoptotic markers. Our results together with previous studies [56,58] showed that dietary RPO can attenuate the harmful effects of cholesterol supplementation in the ischemia/reperfusion model. Our total serum cholesterol results were not increased in the cholesterol fed rats. This was expected, as a previous study employed a similar model of cholesterol feeding in rats, without achieving significant changes in serum cholesterol [103]. The effects of the cholesterol feeding on the cardiovascular system are however clearly discussed in the study of Giricz and coworkers (2003) through the depletion of nitric oxide, and our current study by increased myocardial infarct size [103].

Coronary flow in the Norm group was reduced by $70 \%$, in the Chol group by $64 \%$, in the Chol+RPO group by $57 \%$ and in the Norm+RPO group by $33 \%$ after ischemia. This indicates that RPO attenuated the fall in coronary flow after ischemia. This may suggest that RPO supplementation improves vascular function during reperfusion. 
MMP2 activity was measured before ischemia in the cholesterol supplemented groups and compared to a Norm control group and a RPO supplemented group, as it may be expected that the cholesterol supplemented groups may have increased oxidative stress after supplementation. As increased oxidative stress leads to activation of MMP2 through redox modification of its regulatory subunit, this would be associated with changes in MMP2 activity before ischemia which would be expected to be absent in normal rats [9,19,65-67]. Our results demonstrate for the first time that dietary RPO supplementation may alter myocardial oxidative stress before ischemia in cholesterol fed rats, as MMP2 activity was reduced before ischemia. The reduction in MMP2 activity before ischemia in rats supplemented with both cholesterol and RPO suggests that RPO was able to reduce oxidative stress in these rats. This would most probably be achieved through quenching of ROS, which is generated in greater proportions in cholesterol supplemented rats [14,103]. Increased generation of ROS and oxidative stress would normally be associated with activation of MMP2 [19,65,67]. As increased activity of MMP2 may lead to either cardiac remodeling, or tissue damage [61,71-73], this reduction in MMP2 activity may play a role in RPO mediated protection against ischemia/reperfusion injury. However, MMP2 activity of the Norm +RPO was increased during reperfusion, when compared to normal rats without RPO supplementation. This would normally be associated with increased myocardial susceptibility to ischemia/reperfusion injury [62,74-77]. RPO was able to reduce myocardial infarct size in cholesterol fed rats, despite increased activity of MMP2 in reperfusion found in normal rats. This suggests MMP2 activity may only play a protective role in cholesterol fed rats, and that other protective pathways are responsible for RPO mediated protection in normal rats.

The aim of this study was to investigate whether MMP2 activity was involved in RPO mediated protection of cholesterol fed rat hearts against ischemia/reperfusion. Our results suggest that MMP2 activity may play a role in RPO mediated protection of the hearts of the cholesterol fed rats, but not the hearts of SRC fed rats. This suggests that more pathways of protection may play a role in this protection. Kruger and co-workers (2007) found that RPO supplementation of cholesterol fed rats led to decreased phosphorylation of pro-apoptotic molecules, p38 and JNK [58]. This coincided with increased phosphorylation of the prosurvival kinase ERK early in reperfusion, which leads to reduced apoptosis. Apoptosis has been shown to play a role in the detrimental effects of hypercholesterolemia in the heart. 
Inhibition of apoptosis may therefore, explain the protective effects of RPO in this model $[58]$. 


\section{Summary}

In conclusion, in the study 1, we have demonstrated that oral farnesol treatment reduces ischemia/reperfusion injury. Furthermore, we have shown that the cardioprotective effect of farnesol likely involves increased protein geranylgeranylation and seems to be independent of the other end-products of mevalonate pathway and the antioxidant effect of farnesol.

In study 2 we showed that dietary RPO supplementation attenuated increased susceptibility of cholesterol fed rat hearts to ischemia/reperfusion injury as evidenced by reduced infarct size. Myocardial MMP2 activity was reduced in cholesterol and RPO supplemented rat hearts before ischemia (Figure 10), but not after ischemia (Figure 11) associated with decreased infarct size. This may suggest a different or additional mechanism of protection.

Acute myocardial infarction is currently the leading causes of morbidity and mortality in the world. Myocardial infarction has several risk factors and these risk factors likely lead finally to cardiovascular events. Rapid reclamation of blood flow to the ischemic zone can decrease the mortality of myocardial infarction but it is still high. Therefore, the prevention of myocardial infarction is foremost goal. Here we presented oral pretreatments with two widely used natural food additives which decrease ischemia/reperfusion injury. It may improve the compliance of patients (with risk factors) and increase the effectiveness of prevention of ischemic heart diseases that these materials are natural and orally usable. However, further investigations are needed to understand the mechanism of protective effect of farnesol and RPO. Further understanding of the biochemical mechanism of the protective effect of farnesol and RPO may help to develop new and more effective prevention of acute myocardial infarction. 


\section{Acknowledgement}

This work was supported by a Collaborative Research Grant between Hungary (ZA35/2006) and South Africa (NRF: 62212) and by a grant from the National Innovation Office (5LET_STATIN_08, TAMOP-4.2.2-08/1/2008-0013, TAMOP-4.2.1/B-09/1/KONV-20100005, TÁMOP-4.2.2/B-10/1-2010-0012, TAMOP-4.2.2/A-11/1/KONV-2012-0035, JedlikNKFP-A1-2006-029, Med-Food, Baross DA-TECH-07-2008-0041) and a grant from the Hungarian Scientific Research Fund (OTKA PD 106001). This research was supported by the European Union and the State of Hungary, co-financed by the European Social Fund in the framework of TÁMOP 4.2.4. A/2-11-1-2012-0001 'National Excellence Program'. The red palm oil used in this study was supplied by Carotino SDN BHD (company number: 69046-T), Johar-Bahru, Malaysia.

I greatly acknowledge to Professor László Dux for providing possibility to work at the Biochemistry Department.

I would like to give the expression of my sincere gratitude to my supervisors, Dr. Csaba Csonka and Dr. Tamás Csont for their excellent leadership and supervision. I would also like to thank for their support, patience and encouragement during my $\mathrm{PhD}$ studies.

I would like to thank Professor Peter Ferdinandy, for his valuable guidance and for providing a remarkable insight into my projects. Apart from excellent scientific advice, he greatly helped me improve my analytical thinking, reasoning and presentation skills.

I am thankful to Judit Kovács, Szilvia Török and Nóra Bagi for their skillful assistance.

I would like to give my special thanks to all of my present and past colleagues and friends. Finally, I take this opportunity to acknowledge my family for their support. 


\section{References}

[1] Cohen J. The Global Burden of Disease Study: a useful projection of future global health? J Public Health Med. 2000;22:518-24.

[2] Murray CJ, Lopez AD. Alternative projections of mortality and disability by cause 1990-2020: Global Burden of Disease Study. Lancet. 1997;349:1498-504.

[3] White HD, Chew DP. Acute myocardial infarction. Lancet. 2008;372:570-84.

[4] Tani M, Neely JR. Role of intracellular $\mathrm{Na}^{+}$in $\mathrm{Ca}^{2+}$ overload and depressed recovery of ventricular function of reperfused ischemic rat hearts. Possible involvement of $\mathrm{H}^{+}-\mathrm{Na}^{+}$and $\mathrm{Na}^{+}-\mathrm{Ca}^{2+}$ exchange. Circ Res. 1989;65:1045-56.

[5] Seal JB, Gewertz BL. Vascular dysfunction in ischemia-reperfusion injury. Ann Vasc Surg. 2005;19:572-84.

[6] Turer AT, Hill JA. Pathogenesis of myocardial ischemia-reperfusion injury and rationale for therapy. Am J Cardiol. 2010;106:360-8.

[7] Spinale FG. Matrix metalloproteinases: regulation and dysregulation in the failing heart. Circ Res. 2002;90:520-30.

[8] Hearse DJ, Bolli R. Reperfusion induced injury: manifestations, mechanisms, and clinical relevance. Cardiovasc Res. 1992;26:101-8.

[9] Ferdinandy P, Schulz R, Baxter GF. Interaction of cardiovascular risk factors with myocardial ischemia/reperfusion injury, preconditioning, and postconditioning. Pharmacol Rev. 2007;59:418-58.

[10] Bhatnagar D, Soran H, Durrington PN. Hypercholesterolaemia and its management. BMJ. 2008;337:a993.

[11] Dalen H, Thorstensen A, Romundstad PR, Aase SA, Stoylen A, Vatten LJ. Cardiovascular risk factors and systolic and diastolic cardiac function: a tissue Doppler and speckle tracking echocardiographic study. J Am Soc Echocardiogr. 2011;24:322,32.e6.

[12] Horio T, Miyazato J, Kamide K, Takiuchi S, Kawano Y. Influence of low highdensity lipoprotein cholesterol on left ventricular hypertrophy and diastolic function in essential hypertension. Am J Hypertens. 2003;16:938-44.

[13] Wang TD, Wu CC, Chen WJ et al. Dyslipidemias have a detrimental effect on left ventricular systolic function in patients with a first acute myocardial infarction. Am J Cardiol. 1998;81:531-7. 
[14] Onody A, Csonka C, Giricz Z, Ferdinandy P. Hyperlipidemia induced by a cholesterol-rich diet leads to enhanced peroxynitrite formation in rat hearts. Cardiovasc Res. 2003;58:663-70.

[15] Huang Y, Walker KE, Hanley F, Narula J, Houser SR, Tulenko TN. Cardiac systolic and diastolic dysfunction after a cholesterol-rich diet. Circulation. 2004;109:97-102.

[16] Ferdinandy P, Szilvassy Z, Horvath LI et al. Loss of pacing-induced preconditioning in rat hearts: role of nitric oxide and cholesterol-enriched diet. J Mol Cell Cardiol. 1997;29:3321-33.

[17] Osipov RM, Bianchi C, Feng J et al. Effect of hypercholesterolemia on myocardial necrosis and apoptosis in the setting of ischemia-reperfusion. Circulation. 2009;120:S22-30.

[18] Gorbe A, Varga ZV, Kupai K et al. Cholesterol diet leads to attenuation of ischemic preconditioning-induced cardiac protection: the role of connexin 43. Am J Physiol Heart Circ Physiol. 2011;300:H1907-13.

[19] Kupai K, Szucs G, Cseh S et al. Matrix metalloproteinase activity assays: Importance of zymography. J Pharmacol Toxicol Methods. 2010;61:205-9.

[20] Csont T, Bereczki E, Bencsik P et al. Hypercholesterolemia increases myocardial oxidative and nitrosative stress thereby leading to cardiac dysfunction in apoB-100 transgenic mice. Cardiovasc Res. 2007;76:100-9.

[21] Chu LM, Lassaletta AD, Robich MP et al. Effects of red wine and vodka on collateral-dependent perfusion and cardiovascular function in hypercholesterolemic swine. Circulation. 2012;126:S65-72.

[22] Roach PD, Balasubramaniam S, Hirata F et al. The low-density lipoprotein receptor and cholesterol synthesis are affected differently by dietary cholesterol in the rat. Biochim Biophys Acta. 1993;1170:165-72.

[23] Horton JD, Cuthbert JA, Spady DK. Regulation of hepatic 7 alpha-hydroxylase expression and response to dietary cholesterol in the rat and hamster. $\mathrm{J}$ Biol Chem. 1995;270:5381-7.

[24] Ungi I, Ungi T, Ruzsa Z et al. Hypercholesterolemia attenuates the anti-ischemic effect of preconditioning during coronary angioplasty. Chest. 2005;128:1623-8. 
[25] Kupai K, Csonka C, Fekete V et al. Cholesterol diet-induced hyperlipidemia impairs the cardioprotective effect of postconditioning: role of peroxynitrite. Am J Physiol Heart Circ Physiol. 2009;297:H1729-35.

[26] Goldstein JL, Brown MS. Regulation of the mevalonate pathway. Nature. $1990 ; 343: 425-30$.

[27] Murray RK. Harper's illustrated biochemistry. New York: Lange Medical Books/McGraw-Hill, 2006.

[28] Brown MS, Goldstein JL. Multivalent feedback regulation of HMG CoA reductase, a control mechanism coordinating isoprenoid synthesis and cell growth. J Lipid Res. 1980;21:505-17.

[29] Ong HT. Protecting the heart: a practical review of the statin studies. MedGenMed. 2002;4:1.

[30] Heart Protection Study Collaborative Group. MRC/BHF Heart Protection Study of cholesterol lowering with simvastatin in 20,536 high-risk individuals: a randomised placebo-controlled trial. Lancet. 2002;360:7-22.

[31] Silva MA, Swanson AC, Gandhi PJ, Tataronis GR. Statin-related adverse events: a meta-analysis. Clin Ther. 2006;28:26-35.

[32] Meigs TE, Simoni RD. Farnesol as a regulator of HMG-CoA reductase degradation: characterization and role of farnesyl pyrophosphatase. Arch Biochem Biophys. 1997;345:1-9.

[33] Bentinger M, Grunler J, Peterson E, Swiezewska E, Dallner G. Phosphorylation of farnesol in rat liver microsomes: properties of farnesol kinase and farnesyl phosphate kinase. Arch Biochem Biophys. 1998;353:191-8.

[34] Crick DC, Andres DA, Waechter CJ. Farnesol is utilized for protein isoprenylation and the biosynthesis of cholesterol in mammalian cells. Biochem Biophys Res Commun. 1995;211:590-9.

[35] Ferdinandy P, Csonka C, Csont T, Szilvassy Z, Dux L. Rapid pacing-induced preconditioning is recaptured by farnesol treatment in hearts of cholesterol-fed rats: role of polyprenyl derivatives and nitric oxide. Mol Cell Biochem. 1998;186:27-34. 
[36] Qamar W, Sultana S. Farnesol ameliorates massive inflammation, oxidative stress and lung injury induced by intratracheal instillation of cigarette smoke extract in rats: an initial step in lung chemoprevention. Chem Biol Interact. 2008;176:79-87.

[37] Jahangir T, Khan TH, Prasad L, Sultana S. Farnesol prevents Fe-NTA-mediated renal oxidative stress and early tumour promotion markers in rats. Hum Exp Toxicol. 2006;25:235-42.

[38] Khan R, Sultana S. Farnesol attenuates 1,2-dimethylhydrazine induced oxidative stress, inflammation and apoptotic responses in the colon of Wistar rats. Chem Biol Interact. 2011;192:193-200.

[39] Resh MD. Trafficking and signaling by fatty-acylated and prenylated proteins. Nat Chem Biol. 2006;2:584-90.

[40] Leung KF, Baron R, Seabra MC. Thematic review series: lipid posttranslational modifications. geranylgeranylation of Rab GTPases. J Lipid Res. 2006;47:467-75.

[41] Reddy S, Comai L. Lamin A, farnesylation and aging. Exp Cell Res. 2012;318:17.

[42] Takemoto M, Liao JK. Pleiotropic effects of 3-hydroxy-3-methylglutaryl coenzyme a reductase inhibitors. Arterioscler Thromb Vasc Biol. 2001;21:1712-9.

[43] Aberg F, Appelkvist EL, Dallner G, Ernster L. Distribution and redox state of ubiquinones in rat and human tissues. Arch Biochem Biophys. 1992;295:230-4.

[44] Greenberg S, Frishman WH. Co-enzyme Q10: a new drug for cardiovascular disease. J Clin Pharmacol. 1990;30:596-608.

[45] Hano O, Thompson-Gorman SL, Zweier JL, Lakatta EG. Coenzyme Q10 enhances cardiac functional and metabolic recovery and reduces $\mathrm{Ca}^{2+}$ overload during postischemic reperfusion. Am J Physiol. 1994;266:2174-81.

[46] Doucey MA, Hess D, Cacan R, Hofsteenge J. Protein C-mannosylation is enzyme-catalysed and uses dolichyl-phosphate-mannose as a precursor. Mol Biol Cell. 1998;9:291-300.

[47] Takeda J, Kinoshita T. GPI-anchor biosynthesis. Trends Biochem Sci. 1995;20:367-71.

[48] Kornfeld R, Kornfeld S. Assembly of asparagine-linked oligosaccharides. Annu Rev Biochem. 1985;54:631-64. 
[49] Ferdinandy P, Schulz R. Nitric oxide, superoxide, and peroxynitrite in myocardial ischaemia-reperfusion injury and preconditioning. Br J Pharmacol. 2003;138:532-43.

[50] Yasmin W, Strynadka KD, Schulz R. Generation of peroxynitrite contributes to ischemia-reperfusion injury in isolated rat hearts. Cardiovasc Res. 1997;33:422-32.

[51] Nagendran B, Unnithan UR, Choo YM, Sundram K. Characteristics of red palm oil, a carotene- and vitamin E-rich refined oil for food uses. Food Nutr Bull. 2000;21:189-94.

[52] Sundram K, Sambanthamurthi R, Tan YA. Palm fruit chemistry and nutrition. Asia Pac J Clin Nutr. 2003;12:355-62.

[53] Wilson TA, Nicolosi RJ, Kotyla T, Sundram K, Kritchevsky D. Different palm oil preparations reduce plasma cholesterol concentrations and aortic cholesterol accumulation compared to coconut oil in hypercholesterolemic hamsters. J Nutr Biochem. 2005;16:633-40.

[54] Schroeder MT, Becker EM, Skibsted LH. Molecular mechanism of antioxidant synergism of tocotrienols and carotenoids in palm oil. J Agric Food Chem. 2006;54:3445-53.

[55] van Rooyen J, Esterhuyse AJ, Engelbrecht AM, du Toit EF. Health benefits of a natural carotenoid rich oil: a proposed mechanism of protection against ischaemia/ reperfusion injury. Asia Pac J Clin Nutr. 2008;17 Suppl 1:316-9.

[56] Esterhuyse AJ, du Toit EF, Benade AJ, van Rooyen J. Dietary red palm oil improves reperfusion cardiac function in the isolated perfused rat heart of animals fed a high cholesterol diet. Prostaglandins Leukot Essent Fatty Acids. 2005;72:153-61.

[57] Bester DJ, van Rooyen J, du Toit EF, Esterhuyse AJ. Red palm oil protects against the consequences of oxidative stress when supplemented with dislipidaemic diets. Medical Technology SA. 2006;20:3-10.

[58] Kruger MJ, Engelbrecht AM, Esterhuyse J, du Toit EF, van Rooyen J. Dietary red palm oil reduces ischaemia-reperfusion injury in rats fed a hypercholesterolaemic diet. $\mathrm{Br}$ J Nutr. 2007;97:653-60.

[59] Lalu MM, Csonka C, Giricz Z, Csont T, Schulz R, Ferdinandy P. Preconditioning decreases ischemia/reperfusion-induced release and activation of matrix metalloproteinase- 2 . Biochem Biophys Res Commun. 2002;296:937-41.

[60] Nagase H, Woessner JF,Jr. Matrix metalloproteinases. J Biol Chem. 1999;274:21491-4. 
[61] Wang W, Schulze CJ, Suarez-Pinzon WL, Dyck JR, Sawicki G, Schulz R. Intracellular action of matrix metalloproteinase- 2 accounts for acute myocardial ischemia and reperfusion injury. Circulation. 2002;106:1543-9.

[62] Cheung PY, Sawicki G, Wozniak M, Wang W, Radomski MW, Schulz R. Matrix metalloproteinase-2 contributes to ischemia-reperfusion injury in the heart. Circulation. 2000;101:1833-9.

[63] Lalu MM, Pasini E, Schulze CJ et al. Ischaemia-reperfusion injury activates matrix metalloproteinases in the human heart. Eur Heart J. 2005;26:27-35.

[64] Wang W, Sawicki G, Schulz R. Peroxynitrite-induced myocardial injury is mediated through matrix metalloproteinase-2. Cardiovasc Res. 2002;53:165-74.

[65] Rajagopalan S, Meng XP, Ramasamy S, Harrison DG, Galis ZS. Reactive oxygen species produced by macrophage-derived foam cells regulate the activity of vascular matrix metalloproteinases in vitro. Implications for atherosclerotic plaque stability. J Clin Invest. 1996;98:2572-9.

[66] Okamoto T, Akaike T, Sawa T, Miyamoto Y, van der Vliet A, Maeda H. Activation of matrix metalloproteinases by peroxynitrite-induced protein S-glutathiolation via disulfide S-oxide formation. J Biol Chem. 2001;276:29596-602.

[67] Siwik DA, Pagano PJ, Colucci WS. Oxidative stress regulates collagen synthesis and matrix metalloproteinase activity in cardiac fibroblasts. Am J Physiol Cell Physiol. 2001;280:C53-60.

[68] Svineng G, Ravuri C, Rikardsen O, Huseby NE, Winberg JO. The role of reactive oxygen species in integrin and matrix metalloproteinase expression and function. Connect Tissue Res. 2008;49:197-202.

[69] Hein S, Scheffold T, Schaper J. Ischemia induces early changes to cytoskeletal and contractile proteins in diseased human myocardium. J Thorac Cardiovasc Surg. 1995;110:89-98.

[70] Matsumura Y, Saeki E, Inoue M, Hori M, Kamada T, Kusuoka H. Inhomogeneous disappearance of myofilament-related cytoskeletal proteins in stunned myocardium of guinea pig. Circ Res. 1996;79:447-54.

[71] Gao WD, Atar D, Liu Y, Perez NG, Murphy AM, Marban E. Role of troponin I proteolysis in the pathogenesis of stunned myocardium. Circ Res. 1997;80:393-9. 
[72] Bolli R, Marban E. Molecular and cellular mechanisms of myocardial stunning. Physiol Rev. 1999;79:609-34.

[73] McDonough JL, Arrell DK, Van Eyk JE. Troponin I degradation and covalent complex formation accompanies myocardial ischemia/reperfusion injury. Circ Res. 1999;84:9-20.

[74] Hayashidani S, Tsutsui H, Ikeuchi $M$ et al. Targeted deletion of MMP-2 attenuates early LV rupture and late remodeling after experimental myocardial infarction. Am J Physiol Heart Circ Physiol. 2003;285:H1229-35.

[75] Menon B, Singh M, Singh K. Matrix metalloproteinases mediate beta-adrenergic receptor-stimulated apoptosis in adult rat ventricular myocytes. Am J Physiol Cell Physiol. 2005;289:C168-76.

[76] Bergman MR, Teerlink JR, Mahimkar R et al. Cardiac matrix metalloproteinase-2 expression independently induces marked ventricular remodeling and systolic dysfunction. Am J Physiol Heart Circ Physiol. 2007;292:H1847-60.

[77] Fert-Bober J, Leon H, Sawicka $J$ et al. Inhibiting matrix metalloproteinase-2 reduces protein release into coronary effluent from isolated rat hearts during ischemiareperfusion. Basic Res Cardiol. 2008;103:431-43.

[78] Clark WM, Lessov N, Lauten JD, Hazel K. Doxycycline treatment reduces ischemic brain damage in transient middle cerebral artery occlusion in the rat. $\mathrm{J}$ Mol Neurosci. 1997;9:103-8.

[79] Cursio R, Mari B, Louis K et al. Rat liver injury after normothermic ischemia is prevented by a phosphinic matrix metalloproteinase inhibitor. FASEB J. 2002; 16:93-5.

[80] Roach DM, Fitridge RA, Laws PE, Millard SH, Varelias A, Cowled PA. Upregulation of MMP-2 and MMP-9 leads to degradation of type IV collagen during skeletal muscle reperfusion injury; protection by the MMP inhibitor, doxycycline. Eur J Vasc Endovasc Surg. 2002;23:260-9.

[81] Bendeck MP, Conte M, Zhang M, Nili N, Strauss BH, Farwell SM. Doxycycline modulates smooth muscle cell growth, migration, and matrix remodeling after arterial injury. Am J Pathol. 2002;160:1089-95. 
[82] Krishnamurthy P, Peterson JT, Subramanian V, Singh M, Singh K. Inhibition of matrix metalloproteinases improves left ventricular function in mice lacking osteopontin after myocardial infarction. Mol Cell Biochem. 2009;322:53-62.

[83] Bester DJ, Kupai K, Csont T et al. Dietary red palm oil supplementation reduces myocardial infarct size in an isolated perfused rat heart model. Lipids Health Dis. 2010;9:64.

[84] Kocsis GF, Pipis J, Fekete V et al. Lovastatin interferes with the infarct sizelimiting effect of ischemic preconditioning and postconditioning in rat hearts. Am J Physiol Heart Circ Physiol. 2008;294:2406-9.

[85] Wergeland A, Bester DJ, Sishi BJ, Engelbrecht AM, Jonassen AK, Van Rooyen J. Dietary red palm oil protects the heart against the cytotoxic effects of anthracycline. Cell Biochem Funct. 2011;29:356-64.

[86] Csonka C, Kupai K, Kocsis GF et al. Measurement of myocardial infarct size in preclinical studies. J Pharmacol Toxicol Methods. 2010;61:163-70.

[87] Epstein WW, Lever D, Leining LM, Bruenger E, Rilling HC. Quantitation of prenylcysteines by a selective cleavage reaction. Proc Natl Acad Sci U S A. 1991;88:9668-70.

[88] Rousseau G, Varin F. Determination of ubiquinone-9 and 10 levels in rat tissues and blood by high-performance liquid chromatography with ultraviolet detection. J Chromatogr Sci. 1998;36:247-52.

[89] Dini B, Dolfi C, Santucci V et al. Effects of ageing and increased haemolysis on the levels of dolichol in rat spleen. Exp Gerontol. 2001;37:99-105.

[90] Csont T, Gorbe A, Bereczki E et al. Biglycan protects cardiomyocytes against hypoxia/reoxygenation injury: role of nitric oxide. J Mol Cell Cardiol. 2010;48:649-52.

[91] Li X, Heinzel FR, Boengler K, Schulz R, Heusch G. Role of connexin 43 in ischemic preconditioning does not involve intercellular communication through gap junctions. J Mol Cell Cardiol. 2004;36:161-3.

[92] Ali BR, Nouvel I, Leung KF, Hume AN, Seabra MC. A novel statin-mediated "prenylation block-and-release" assay provides insight into the membrane targeting mechanisms of small GTPases. Biochem Biophys Res Commun. 2010;397:34-41.

[93] Lane KT, Beese LS. Thematic review series: lipid posttranslational modifications. Structural biology of protein farnesyltransferase and geranylgeranyltransferase type I. J Lipid Res. 2006;47:681-99. 
[94] Brar BK, Jonassen AK, Egorina EM et al. Urocortin-II and urocortin-III are cardioprotective against ischemia reperfusion injury: an essential endogenous cardioprotective role for corticotropin releasing factor receptor type 2 in the murine heart. Endocrinology. 2004;145:24-35.

[95] Xiang SY, Vanhoutte D, Del Re DP et al. RhoA protects the mouse heart against ischemia/reperfusion injury. J Clin Invest. 2011;121:3269-76.

[96] Dougherty CJ, Kubasiak LA, Frazier DP et al. Mitochondrial signals initiate the activation of c-Jun N-terminal kinase (JNK) by hypoxia-reoxygenation. FASEB J. 2004; 18:1060-70.

[97] Matejikova J, Kucharska J, Pancza D, Ravingerova T. The effect of antioxidant treatment and NOS inhibition on the incidence of ischemia-induced arrhythmias in the diabetic rat heart. Physiol Res. 2008;57 Suppl 2:55-60.

[98] Molyneux SL, Florkowski CM, Richards AM, Lever M, Young JM, George PM. Coenzyme Q10; an adjunctive therapy for congestive heart failure? N Z Med J. 2009;122:749 .

[99] Kapusta L, Zucker N, Frenckel G et al. From discrete dilated cardiomyopathy to successful cardiac transplantation in congenital disorders of glycosylation due to dolichol kinase deficiency (DK1-CDG). Heart Fail Rev. 2012;18:187-96.

[100] Lefeber DJ, de Brouwer AP, Morava E et al. Autosomal recessive dilated cardiomyopathy due to DOLK mutations results from abnormal dystroglycan Omannosylation. PLoS Genet. 2011;7:e1002427.

[101] Chagas CE, Vieira A, Ong TP, Moreno FS. Farnesol inhibits cell proliferation and induces apoptosis after partial hepatectomy in rats. Acta Cir Bras. 2009;24:377-82.

[102] Joo JH, Liao G, Collins JB, Grissom SF, Jetten AM. Farnesol-induced apoptosis in human lung carcinoma cells is coupled to the endoplasmic reticulum stress response. Cancer Res. 2007;67:7929-36.

[103] Giricz Z, Csonka C, Onody A, Csont T, Ferdinandy P. Role of cholesterolenriched diet and the mevalonate pathway in cardiac nitric oxide synthesis. Basic Res Cardiol. 2003;98:304-10. 